\title{
Lignocellulose degradation at the holobiont level: teamwork in a keystone soil invertebrate
}

\author{
Marius Bredon', Jessica Dittmer ${ }^{1,2}$, Cyril Noël ${ }^{1}$, Bouziane Moumen ${ }^{1}$ and Didier Bouchon ${ }^{1 *}$ (D)
}

\begin{abstract}
Background: Woodlice are recognized as keystone species in terrestrial ecosystems due to their role in the decomposition of organic matter. Thus, they contribute to lignocellulose degradation and nutrient cycling in the environment together with other macroarthropods. Lignocellulose is the main component of plants and is composed of cellulose, lignin and hemicellulose. Its digestion requires the action of multiple CarbohydrateActive enZymes (called CAZymes), typically acting together as a cocktail with complementary, synergistic activities and modes of action. Some invertebrates express a few endogenous lignocellulose-degrading enzymes but in most species, an efficient degradation and digestion of lignocellulose can only be achieved through mutualistic associations with endosymbionts. Similar to termites, it has been suspected that several bacterial symbionts may be involved in lignocellulose degradation in terrestrial isopods, by completing the CAZyme repertoire of their hosts.

Results: To test this hypothesis, host transcriptomic and microbiome shotgun metagenomic datasets were obtained and investigated from the pill bug Armadillidium vulgare. Many genes of bacterial and archaeal origin coding for CAZymes were identified in the metagenomes of several host tissues and the gut content of specimens from both laboratory lineages and a natural population of A. vulgare. Some of them may be involved in the degradation of cellulose, hemicellulose, and lignin. Reconstructing a lignocellulose-degrading microbial community based on the prokaryotic taxa contributing relevant CAZymes revealed two taxonomically distinct but functionally redundant microbial communities depending on host origin. In parallel, endogenous CAZymes were identified from the transcriptome of the host and their expression in digestive tissues was demonstrated by RT-qPCR, demonstrating a complementary enzyme repertoire for lignocellulose degradation from both the host and the microbiome in A. vulgare.
\end{abstract}

Conclusions: Our results provide new insights into the role of the microbiome in the evolution of terrestrial isopods and their adaptive radiation in terrestrial habitats.

Keywords: Microbiome, Transcriptome, CAZyme, Holobiont, Host-symbiont interactions, Isopods, RT-qPCR

\section{Background}

Plant biomass decomposition represents a key step in the terrestrial carbon cycle $[1,2]$ that is carried out by the combined action of fungi, microbes, and decomposer animals such as "litter transformer" macroarthropods [3, 4]. Plants,

\footnotetext{
*Correspondence: didier.bouchon@univ-poitiers.fr; http://ebi.labo.univpoitiers.fr/

${ }^{1}$ Laboratoire Ecologie et Biologie des Interactions-UMR CNRS 7267, Equipe Ecologie Evolution Symbiose-Batiment B8-B35, Université de Poitiers, 5 rue Albert Turpain, TSA 51106, F-86073 Poitiers Cedex 9, France

Full list of author information is available at the end of the article
}

and by extension dead plant biomass, are mostly composed of lignocellulose, making it the most abundant biomass component on Earth. Thus, the process of lignocellulose degradation is of great research interest, especially for biotechnology, due to its potential as a sustainable resource for biofuels and biomaterial production [5-7].

Lignocellulose is composed of cellulose, hemicellulose, and lignin. The degradation of these polymers requires the synergistic action of multiple Carbohydrate-Active enZyme (called CAZymes) families, typically acting together as an enzyme cocktail with multiple complementary and

(c) The Author(s). 2018 Open Access This article is distributed under the terms of the Creative Commons Attribution 4.0 International License (http://creativecommons.org/licenses/by/4.0/), which permits unrestricted use, distribution, and 
coordinated oxidative, hydrolytic and non-hydrolytic activities $[7,8]$. Since lignin, a complex heteropolymer providing strength and resistance to plant tissues [9], protects carbohydrate polymers against enzymatic digestion, its degradation is a critical first step in lignocellulose degradation enabling the liberation of cellulose and hemicellulose $[10,11]$. Many enzymes are known as lignin-modifying enzymes (LMEs): lignin peroxidases, manganese peroxidases, versatile peroxidases, laccases and cellobiose dehydrogenases [12]. Cellulose, on the other hand, is a polymer of several glucose monomers linked by ß-1,4-glycosidic bonds, necessary for the rigid structure of plant cell walls [13]. Commonly, a set of three enzymes is required for the hydrolysis of cellulose into glucose monomers: (1) endoglucanases, (2) exoglucanases, and (3) $\beta$-glucosidases [14]. Finally, hemicellulose is a complex polysaccharide with large variations both within and between plant species and plant tissues. Hemicellulases can be classified in three types [15]: (1) endo-hemicellulases which cleave the main chain internally, (2) exo-hemicellulases which release monomeric sugars, and (3) debranching enzymes (also known as accessory enzymes) which cleave the side chains of the polymers or associated oligosaccharides.

In nature, fungi and bacteria are the main producers of enzymes which decompose lignocellulose, making them the most important players in plant biomass degradation $[16,17]$. Lignocellulose decomposition is a rare trait among animals, since most plants have evolved structural and chemical mechanisms of resistance against attacks by herbivores [6]. Furthermore, there is no animal genome known to date that encodes all necessary enzymes to break down plant polysaccharides into sugar monomers [18]. Many animals possess a few lignocellulose-degrading enzymes [19, 20], but in most cases, an efficient degradation of lignocellulose is only achieved through mutualistic associations with microbial symbionts [21]. Lignocellulose degradation in these animals is thus achieved at the holobiont level (i.e., a host and its associated microbiota [22]), relying on the complementary action of the lignocellulose-degrading enzyme repertoire from the host and its associated microbial symbionts. In invertebrates, termites represent the most studied model system for the process of lignocellulose degradation. Due to a spatial, complementary and synergistic cooperation between the host and its microbiome [23-26], termites are able to digest lignocellulose with a high efficiency, making them one of the most powerful animal species for this process [27, 28]. Other macroarthropods such as millipedes [29] or terrestrial isopods [30,31] are also known to contribute significantly to the decomposition of lignocellulose, but the respective roles of the host and the symbionts for lignocellulose digestion in these species are still unknown.
Terrestrial isopods are recognized as keystone species in terrestrial ecosystems due to their important role in the decomposition of organic matter [32]. They contribute directly to litter decomposition and nutrient cycling by digesting substrates [33-35], and indirectly through their feces which affect the soil microbial community and its activity [30, 36, 37]. Zimmer et al. [38, 39] hypothesized that the gut microbiota had facilitated or even enabled the colonization of land by terrestrial isopods, by contributing the necessary enzymes for the digestion of terrestrial food sources. Specifically, it has been suggested that terrestrial isopods are able to exploit lignocellulose with the help of hepatopancreatic (i.e., resident in the caeca) and/or environmental bacteria [38-42]. While several bacterial symbionts were indeed identified in the caeca of diverse isopod species (i.e., Candidatus Hepatincola porcellionum [43] and Candidatus Hepatoplasma crinochetorum [44, 45]) and were initially hypothesized to be involved in lignocellulose digestion (reviewed in $[42,46]$ ), their exact functions within the isopod holobiont still remain to be elucidated. Moreover, the subsequent discovery of endogenous cellulases in isopods [47-49] raised questions regarding the role of the isopod gut microbiota in lignocellulose digestion.

In the present study, we address this question by combining for the first time transcriptomic and shotgun metagenomic approaches in the common pill-bug Armadillidium vulgare. This species is known to harbor a high diversity of bacteria in various tissues [50-52] and thus represents an excellent model to study diverse symbiotic interactions [42]. To this end, metagenomes from several tissues and the gut content of specimens from both laboratory lineages and a natural population were sequenced and used to identify lignocellulose-degrading CAZymes of prokaryotic origins. In parallel, host lignocellulose-degrading CAZymes were identified in the transcriptome of $A$. vulgare, and their expression in host tissues was verified by RT-qPCR. This work allowed us to (i) describe the enzyme repertoire implicated in lignocellulose degradation in the $A$. vulgare holobiont, (ii) identify microbial taxa contributing lignocellulose-degrading genes, and (iii) unveil potential interactions between host and symbionts enabling an efficient lignocellulose digestion.

\section{Methods \\ Biological samples}

Transcriptomic data were generated from A. vulgare females originating from 10 populations that are maintained in the laboratory in population cages (Table 1). In the laboratory, all animals were kept at $20{ }^{\circ} \mathrm{C}$ and natural photoperiod in plastic breeding boxes on moistened potting mix and fed ad libitum with lime tree leaves and carrot slices. 
Table 1 A. vulgare samples used for the reference transcriptome and assembly statistics

\begin{tabular}{|c|c|c|c|c|c|}
\hline \multicolumn{6}{|l|}{ Samples } \\
\hline Origin & Wolbachia status & Gender & $N$ & GenBank & No. of reads \\
\hline Celles sur Belle, France & + & $\mathrm{F}$ & 1 & SRS625835 & $3,881,922$ \\
\hline Vancouver, Canada & + & $\mathrm{F}$ & 1 & SRS625837 & $7,081,881$ \\
\hline Mentrida, Spain & - & $\mathrm{F}$ & 1 & SRS625838 & $8,768,792$ \\
\hline Heraklion, Greece & - & $\mathrm{F}$ & 1 & SRS625839 & $28,956,650$ \\
\hline Fornazo, Italia & - & $\mathrm{F}$ & 1 & SRS625840 & $8,826,638$ \\
\hline Helsingör, Denmark & + & $\mathrm{F}$ & 1 & SRS625841 & $7,520,054$ \\
\hline Porto Alegre, Brazil & - & $\mathrm{F}$ & 1 & SRS625842 & $13,957,815$ \\
\hline Germany & - & $\mathrm{F}$ & 1 & SRS625843 & $8,824,057$ \\
\hline Prague, Czech Republic & + & $\mathrm{F}$ & 1 & SRS625844 & $35,468,027$ \\
\hline Saint Guilhem, France & + & $\mathrm{F}$ & 1 & SRS625845 & $10,874,926$ \\
\hline Total & & & & & $134,160,762$ \\
\hline \multicolumn{6}{|l|}{ Statistics } \\
\hline \multicolumn{4}{|l|}{ Parameters } & \multicolumn{2}{|c|}{ Number of sequences } \\
\hline \multicolumn{4}{|l|}{ Total number of bases } & \multicolumn{2}{|l|}{$104,530,589$} \\
\hline \multicolumn{2}{|c|}{ Total number of transcripts } & & & \multicolumn{2}{|l|}{143,383} \\
\hline \multicolumn{3}{|c|}{ Total number of transcripts after removing Prokaryotes and viruses } & & \multicolumn{2}{|l|}{142,909} \\
\hline \multicolumn{3}{|l|}{ Mean GC count } & & \multicolumn{2}{|l|}{$36 \%$} \\
\hline \multicolumn{3}{|l|}{ N50 } & & \multicolumn{2}{|l|}{1805} \\
\hline \multicolumn{3}{|l|}{ Mean length } & & \multicolumn{2}{|l|}{685} \\
\hline \multicolumn{3}{|c|}{$\%$ reads used for assembly } & & \multicolumn{2}{|l|}{$95.85 \%$} \\
\hline \multicolumn{3}{|c|}{ Total number of predicted ORFs } & & \multicolumn{2}{|l|}{43,672} \\
\hline
\end{tabular}

Metagenomic data were generated from two laboratory lineages (one Wolbachia-free, the other harboring the feminizing strain $w \mathrm{VulC}, N=22$ individuals) and one field population (10 males and 10 females) of $A$. vulgare (Table 2). Individuals from the field were collected in 2012 and 2014 at Availles (France, $46^{\circ} 51^{\prime} 37^{\prime \prime}$ N, $0^{\circ} 8^{\prime} 28^{\prime \prime} \mathrm{E}$ ) and were kept in plastic boxes with soil and leaves from their respective sampling site until dissection within 2 days after collection. Isopods collected in 2012 were the same as in our previous metabarcoding studies $[51,52]$. Wolbachia infection status was determined for all individuals via PCR and sequencing of the wsp gene.

\section{Transcriptomics: RNA extraction and sequencing}

Total RNA was extracted from one whole adult female from each population. Each individual was frozen in liquid nitrogen and grinded with a mortar and pestle. The resulting powders were processed using TRIzol ${ }^{\circ}$ Reagent (Invitrogen) to extract RNA according to the manufacturer's protocol. Quantity and quality of total RNA were determined using agarose gel electrophoresis, NanoDrop spectrophotometer (ThermoFisher) and Bioanalyzer (Agilent). The extracted materials were stored at $-80{ }^{\circ} \mathrm{C}$ until use.
Single-end sequencing libraries were constructed, after mRNA enrichment based on the existence of poly (A) tails and sequenced by the "Institut des Sciences et de l'Évolution" (Montpellier, France) on the Illumina HiSeq 2000 sequencing platform to produce $50 \mathrm{bp}$ single-end reads. These reads have been used previously in a transcriptome-based population genomics study [53]. The total number of reads obtained ranged from 3,881,922 to $35,468,027$ depending on the library (Table 1). The raw reads are available in SRA archive under accession numbers SRS625835 and SRS625837-SRS625845.

\section{De novo host transcriptome assembly}

Read quality was checked with FastQC (version 0.11.2; http://www.bioinformatics.babraham.ac.uk/projects/fastqc). To identify and remove mitochondrial contaminants, reads were aligned against the $A$. vulgare mitogenome (accession number EF643519.3) using Bowtie (version 1.1.0; [54]). Removal of sequencing adaptors and undetermined nucleotides were performed with FASTX-Toolkit (version 0.0.13; http://hannonlab.cshl.edu/fastx_toolkit/index.html) and Cutadapt (version 1.9; [55]). Reads shorter than 35 bp were removed. Cleaned reads from each library were assembled using Velvet (version 1.2.08; [56]) and Oases 
Table 2 Metrics of the A. vulgare metagenome assemblies

\begin{tabular}{|c|c|c|c|c|c|c|c|c|c|c|}
\hline Origin & $N$ & Gender & Wolbachia & Tissues & No. of reads & No. of contigs & N50 & $\%$ reads used & No. of predicted ORFs ${ }^{1}$ & No. of LDC $^{*}$ \\
\hline Laboratory & 7 & M & - & Tissue samples* & $93,016,946$ & 545,551 & 575 & 79.3 & 173,550 & 1 \\
\hline Laboratory & 7 & M & - & Hindgut & $151,479,496$ & 862,485 & 745 & 85.2 & 300,044 & 1 \\
\hline Laboratory & 7 & M & - & Gut content & $44,025,120$ & 181,858 & 490 & 60.5 & 77,326 & 135 \\
\hline Laboratory & 8 & $\mathrm{~F}$ & - & Tissue samples* & $115,690,244$ & 617,032 & 638 & 82.6 & 198,980 & 0 \\
\hline Laboratory & 8 & $\mathrm{~F}$ & - & Hindgut & $213,961,342$ & 919,075 & 727 & 86.1 & 309,351 & 4 \\
\hline Laboratory & 8 & $\mathrm{~F}$ & - & Gut content & $85,069,086$ & 460,039 & 516 & 70 & 165,226 & 92 \\
\hline Laboratory & 7 & $\mathrm{~F}$ & + & Tissue samples* & $136,360,100$ & 714,448 & 647 & 84.5 & 238,023 & 32 \\
\hline Laboratory & 7 & $\mathrm{~F}$ & + & Hindgut & $196,487,170$ & 960,311 & 760 & 90 & 321,849 & 6 \\
\hline Laboratory & 7 & $\mathrm{~F}$ & + & Gut content & $61,471,292$ & 284,429 & 502 & 65.1 & 101,524 & 72 \\
\hline Availles & 10 & M & - & Tissue samples* & $133,995,390$ & 708,519 & 707 & 85.7 & 229,060 & 2 \\
\hline Availles & 10 & M & - & Hindgut & $211,001,880$ & 857,462 & 747 & 87.7 & 286,800 & 7 \\
\hline Availles & 10 & M & - & Gut content & $36,755,870$ & 19,887 & 513 & 10.1 & 20,111 & 46 \\
\hline Availles & 10 & $F$ & + & Tissue samples* & $144,043,638$ & 692,481 & 658 & 85.7 & 230,975 & 13 \\
\hline Availles & 10 & $\mathrm{~F}$ & + & Hindgut & $212,185,430$ & 920,773 & 814 & 90.4 & 314,895 & 17 \\
\hline Availles & 10 & $\mathrm{~F}$ & + & Gut content & $55,605,558$ & 200,488 & 452 & 52.7 & 67,468 & 36 \\
\hline
\end{tabular}

$L D C$, lignocellulose-degrading CAZymes

*Tissue samples: caeca, nerve cords, gonads, and hemolymph

${ }^{1}$ ORFs, predicted ORFs after filtering

(version 0.2.08; [57]) with 11 values of $k$-mers (27-47). Assemblies were then merged, and redundancy was removed by clustering transcripts with $\geq 90 \%$ identity from each $k$-mer using CD-HIT-EST (version 4.6; [58]).

To remove transcripts corresponding to possible prokaryotes and viruses, transcripts were compared with the non-redundant protein database (1 March 2017) using BLASTx [59] with an $E$ value cut-off of 0.0001. All transcripts identified as prokaryotes or viruses were removed from the transcriptome. The quality of the resulting assembly was assessed with BUSCO (version 3.0.1; [60]) referring to core arthropod genes. The coverage of each transcript was calculated as reads per kilo base per million mapped reads (RPKM [61]).

\section{Metagenomics: DNA extraction and sequencing}

Prior to dissection, all individuals were surface sterilized using sodium hypochlorite and hemolymph was collected after piercing the cuticle with a sterile needle. Several tissues (i.e., hindgut, caeca, nerve cords, and gonads) were then dissected out using sterilized instruments and rinsed in Ringer solution to avoid cross-contamination between tissues. In order to separate the hindgut tissue from the gut content, the bulk of the gut content was squeezed out of the hindgut into a $1.5 \mathrm{ml}$ microcentrifuge tube containing extraction buffer (100 mM Tris [pH 8.0], $100 \mathrm{mM}$ EDTA, $100 \mathrm{mM} \mathrm{NaCl}$, $0.1 \%$ SDS, $50 \mathrm{mM}$ DTT, $1.25 \%$ Proteinase K) using sterile forceps. Subsequently, the hindgut was cut longitudinally and washed in Ringer solution to remove remaining gut content.
All hemolymph, tissue, and gut content samples were then homogenized in extraction buffer, and total DNA was purified using phenol-chloroform [62]. Equimolar amounts of DNA from 7 to 10 biological replicates of the same tissue and sample type (i.e., origin, gender, Wolbachia infection status) were pooled and prokaryotic DNA was enriched in each pool using the NEBNext ${ }^{\circ}$ Microbiome DNA Enrichment kit (New England Biolabs) according to the manufacturer's instructions. The enriched DNA was quantified using PicoGreen (Invitrogen). To reduce the number of samples for sequencing, enriched DNA from hemolymph, gonads, nerve cords, and caeca (i.e., all tissues except the hindgut) were pooled in equimolar amounts for each sample type (hereafter referred to as "tissue samples"), while enriched DNA from the hindgut and the gut content were kept as separate samples. This resulted in 15 shotgun metagenomic libraries which were sequenced on an Illumina HiSeq 2500 by GenoScreen (Lille, France), generating $2 \times 100$ bp paired-end reads. The total number of reads obtained for each library ranged from $36,755,870$ to $213,961,342$ (Table 2).

\section{Metagenomic shotgun data analysis}

Read quality was checked with FastQC (version 0.11.2) and low-quality reads and sequencing adaptors were removed using Trimmomatic (version 0.32; [63]). Trimmed reads shorter than $35 \mathrm{bp}$ were discarded. High quality reads from each library were assembled using MegaHit (version 1.0.3; [64]) with default parameters. 
To remove host, eukaryote and virus contigs from the metagenome assemblies, contigs were searched against the $A$. vulgare reference transcriptome and the non-redundant protein database (1 April 2017) using BLASTn and BLASTx, respectively [59]. The minimum $E$ value was set at 0.0001 , and all contigs that matched to viruses, A. vulgare and other eukaryotes, were removed from the final metagenome assemblies.

\section{Carbohydrate-Active enZyme annotation}

A. vulgare transcripts and metagenomic contigs encoding CAZymes were identified using the Carbohydrate Active enZymes (CAZy) database [65]. Prior to identification, all open reading frames (ORFs) were predicted for both the $A$. vulgare reference transcriptome and the metagenome assemblies using Transdecoder (version 3.0.1; https://github.com/TransDecoder/) and MetaProdigal (version 2.60; [66]), respectively, with default parameters for both. Subsequently, dbCAN [67], a database which uses hidden Markov models to define the signature domains for every CAZy family (i.e., glycoside hydrolases (GHs), Glycosyltransferases (GTs), polysaccharide lyases (PLs), carbohydrate esterases (CEs), auxiliary activities (AAs), and carbohydrate-binding modules (CBMs)) was used to identify CAZymes. All predicted ORFs were analyzed with dbCAN (1 March 2017) using HMMER (version 3.1b2; [68]) with an $E$ value threshold of 0.0001. ORFs identified as CAZymes were then imported into Hotpep [69] to predict their enzymatic activity.

\section{Taxonomic assignment of identified CAZymes}

For the genes annotated as CAZymes in metagenome assemblies, searches against the non-redundant protein database (1 April 2017) were performed using BLASTp [59]. An $E$ value cut-off of 0.0001 was used and the top five hits were kept. The BLAST outputs were then imported into MEGAN6 software [70] for taxonomic assignment using the NCBI taxonomy database. Each ORF was thus assigned to the most accurate taxonomic rank (i.e., kingdom, phylum, class, order, family, genus, and species) based on the LCA (i.e., lowest common ancestor) algorithm. Results were visualized using the Phyloseq R package [71] and Circos software [72].

\section{Quantitative RT-PCR}

The expression of 16 transcripts representing all lignocellulose-degrading CAZy families identified in the host transcriptome was verified by real-time quantitative reverse transcription PCR (RT-qPCR). Annotated transcripts with high RPKM values were chosen as representative of a given family. Three males and three females from Celles sur Belle,
Heraklion, and Prague (Table 1) populations were used for dissections. Total RNA was extracted from their digestive tissues (i.e., caeca, hindgut, hindgut content) as well as non-digestive tissues (i.e., gonads, nerve cords, fat tissues) as described above for transcriptome sequencing. First-strand cDNA was synthesized using the SuperScript ${ }^{\mathrm{tm}}$ IV First-Strand Synthesis System kit (Invitrogen) according to the manufacturer's protocol, with $500 \mathrm{ng}$ of total RNA as template and using random hexamer primers. Specific primers for genes of interest were designed based on our transcripts with PRIMER3 software [73]. Gene-specific primers are listed in Additional file 1: Table S1. Quantitative RT-PCR was performed using the LightCycler LC480 system (Roche) as follows: $10 \mathrm{~min}$ at $95{ }^{\circ} \mathrm{C}$ followed by 45 cycles of $10 \mathrm{~s}$ at $95^{\circ}$ $\mathrm{C}, 10 \mathrm{~s}$ at $60{ }^{\circ} \mathrm{C}$, and $20 \mathrm{~s}$ at $72{ }^{\circ} \mathrm{C}$. A melting curve $\left(65{ }^{\circ} \mathrm{C}\right.$ to $97{ }^{\circ} \mathrm{C}$ ) was recorded at the end of each reaction to check that the PCR product was unique. Each reaction mixture contained $6 \mu$ SYBR Green I Master Mix (Roche), $0.6 \mu \mathrm{l}$ of each forward and reverse primer $(10 \mu \mathrm{M}), 2.4 \mu \mathrm{l}$ of nuclease-free water and $1.5 \mu \mathrm{l}$ of cDNA template. Expression levels of target genes were normalized based on the expression level of two reference genes: Ribosomal Protein L8 (RbL8) and Elongation Factor 2 (EF2) [74]. Gene expression levels in the different tissues were compared using the nonparametric Kruskal-Wallis rank sum test in combination with Dunn's post hoc multiple comparison test with Benjamini-Hochberg correction (PMCMR $\mathrm{R}$ package, $\mathrm{R}$ software version 3.4.0; https://www.r-project.org/).

\section{Results}

\section{Quality of transcriptome and metagenome assemblies}

The reference transcriptome of $A$. vulgare was produced using Illumina short reads technology in single-end mode, from 10 libraries generating a total of 134,160,762 reads (Table 1). After assembly, 143,383 transcripts were obtained with an N50 of 1805 . Identified transcripts from prokaryotes and viruses (441 and 33 respectively) were removed from the assembly. Statistics of the final transcriptome are given in Table 1. Assembly completeness was evaluated using the BUSCO pipeline [60]. From the 1066 single-copy orthologous arthropod genes contained in the BUSCO database, 1021 (95.7\%) complete genes (638 single-copy genes and 383 duplicated) and 25 fragmented genes $(2.3 \%)$ were represented in the $\mathrm{A}$. vulgare reference transcriptome assembly and only 20 genes were missing (2\%). Thus, the multiple $k$-mer method we used for the assembly of the $A$. vulgare reference transcriptome led to a highly complete transcriptome.

The 15 metagenomes obtained from different host tissues as well as the gut content of $A$. vulgare generated a 
total of 1,891,148,562 Illumina reads. These were assembled into 19,887-960,311 contigs depending on the library (Table 2). The gut content metagenomes had lower numbers of reads, assembled contigs, and N50 values compared to metagenomes from host tissues (Table 2), indicating their complexity and taxonomic richness. In contrast, there was no difference in the number of reads, assembled contigs and N50 for metagenomes obtained from the hindgut and tissue samples. Furthermore, there was no difference between laboratory and field metagenome assemblies.

\section{Identification of CAZymes in the A. vulgare holobiont}

The $A$. vulgare reference transcriptome assembly and the metagenome assemblies were screened for genes encoding CAZymes (Carbohydrate Active enZymes). Since CAZymes are characteristically modular in structure, and each CAZyme can contain several modules with distinct functions, we refer to modules rather than to the proteins in which they are contained. CAZy modules typically retain their functions when they are expressed, independent of the remaining protein regions. The dbCAN pipeline identified 1933 CAZy modules in the A. vulgare reference transcriptome and 3421 CAZy modules in the 15 metagenome assemblies (Additional file 2: Table S2; Additional files 3 and 4). RPKM values for CAZymes identified in the host transcriptome are given in Additional file 5: Table S3. The CAZyme-associated genes were classified into enzyme families according to the CAZy nomenclature (http://www.cazy.org/; [65]). A total of 231 CAZy families were identified in the A. vulgare holobiont, distributed across all known CAZy classes (i.e., GHs, GTs, PLs, CEs, AAs, and CBMs) (Additional file 2: Table S2). Among them, 36 and 133 families were specific to the host and its microbiome, respectively, and 62 families were present in both. Enzymatic activities of the identified CAZymes were predicted by Hotpep and listed in Additional file 6: Table S4.

The carbohydrate-binding modules (CBMs) were the most prevalent class in the A. vulgare holobiont with 63 different families, corresponding to 1200 and 1017 modules in the microbiome and the host, respectively. Among the most abundant CAZymes, the CBM14 family, a chitin binding module, was prominent in the host with 940 modules representing $48.6 \%$ of the total host CAZy modules, while it was only represented by 26 modules in the microbiome ( $0.008 \%$ of the microbiome CAZy modules). In contrast, the CBM47 family, a fucose-binding module, represented $18.4 \%$ of the total microbiome CAZy modules with 629 modules, whereas it represented only $0.004 \%$ of CAZy modules with 8 modules in the host transcriptome. The second most prominent class of CAZymes in the $A$. vulgare holobiont was the class of Glycosyltransferases (GTs), with 866 and 338 modules in the microbiome and the host, respectively, together representing 63 different families. Eight hundred eighty-seven modules in the microbiome and 403 in the host were associated with the class of glycoside hydrolases (GHs), distributed across 72 families. GHs with known chitinase and lysozyme activities were the most abundant both in the microbiome (GH23 = 119 modules) and in the host (GH18 = 128 modules). Moreover, 13 families of carbohydrate esterases (CEs) were represented by 328 and 155 modules in the microbiome and in the host, respectively. Among these, CE1 and CE10 families were the most abundant CE families in the $A$. vulgare holobiont, together representing $76.8 \%$ (119 modules) of the CEs in the host and $45.4 \%$ (149 modules) in the microbiome. The class auxiliary activities (AAs) was represented by 6 families, accounting for 85 modules in the microbiome and 17 modules in the host. Finally, polysaccharide lyases (PLs) belonging to 14 different PL families were the least abundant, with 55 modules in the microbiome and only 3 in the host.

\section{Lignocellulose-degrading CAZymes}

Selected CAZymes known as lignocellulose-degrading enzymes and CBMs known as lignocellulose-binding modules were then examined in depth, due to their potential nutritional role in A. vulgare. In total, we identified 707 modules corresponding to a total of 38 lignocellulose-degrading CAZy families in the A. vulgare holobiont (506 modules in the microbiome and 201 in the host, Table 3). Among these, 21 families were specific to the microbiome, 4 were found only in the host, and 13 were present in both. A comparison of the glycoside hydrolase $(\mathrm{GH})$ profiles of the $A$. vulgare microbiome and other animal gut microbiomes (inspired by the classification of Cardoso et al. [75] and Allgaier et al. [76]) is given in Additional file 7: Table S5. Overall, the $\mathrm{GH}$ profile of the $A$. vulgare microbiome is very similar to other animal gut microbiomes, except for mannases and debranching enzymes: the former are more abundant in the A. vulgare microbiome compared to other organisms, while the latter are less abundant. In addition, we identified 932 modules corresponding to 39 lignocellulose-binding module families (875 modules in the microbiome and 57 in the host, Table 3).

The majority of the lignocellulose-degrading CAZymes identified in the microbiome were found in the gut content, representing $82.2 \%(N=416)$ of the modules identified as cellulases, hemicellusases, and lignin-modifying enzymes (LMEs), whereas only $7.1 \%$ of the modules were identified in the hindgut $(N=36)$ and $10.7 \%$ in the tissues $(N=54)$ (Table 4). Among the 34 lignocellulose-degrading CAZy families found in the microbiome, 17 were present in all samples (tissue samples, hindgut, and gut content) and 14 were specific to the gut content. Three families were not found in the gut content: GH11 was specific to the hindgut, 
Table 3 List of CAZymes implicated in lignocellulose degradation in the A. vulgare holobiont. Presented are the total numbers of CAZy modules for each family in the host reference transcriptome and in the metagenome assemblies

\begin{tabular}{|c|c|c|c|c|c|}
\hline \multirow[t]{2}{*}{ CAZy family } & \multirow[t]{2}{*}{ Known activities } & \multirow[t]{2}{*}{ Host } & \multicolumn{3}{|c|}{$\begin{array}{l}\text { Metagenome } \\
\text { assemblies }\end{array}$} \\
\hline & & & Field & $\mathrm{Lab}$ & Total \\
\hline \multicolumn{2}{|l|}{ LMEs } & 15 & 4 & 25 & 29 \\
\hline AA1 & Laccase & 2 & - & - & - \\
\hline AA2 & $\begin{array}{l}\text { Manganese peroxidase; versatile } \\
\text { peroxidase; lignin peroxidase }\end{array}$ & - & - & 16 & 16 \\
\hline AA3 & Cellobiose dehydrogenase & 13 & 4 & 9 & 13 \\
\hline \multicolumn{2}{|l|}{ Hemicellulases } & 121 & 86 & 226 & 321 \\
\hline CE1 & $\begin{array}{l}\text { Acetyl xylan esterase; } \\
\text { feruloyl esterase }\end{array}$ & 33 & 29 & 61 & 90 \\
\hline CE3 & Acetyl xylan esterase & 19 & 7 & 19 & 26 \\
\hline CE4 & Acetyl xylan esterase & 13 & 23 & 32 & 55 \\
\hline CE5 & Acetyl xylan esterase & - & 1 & 1 & 2 \\
\hline CE6 & Acetyl xylan esterase & - & - & 2 & 2 \\
\hline CE7 & Acetyl xylan esterase & - & 4 & 1 & 5 \\
\hline CE12 & Acetyl xylan esterase & 2 & 1 & 5 & 6 \\
\hline $\mathrm{GH} 2$ & $\begin{array}{l}\beta \text {-galactosidase; } \beta \text {-mannosidase; } \\
\text { a-L-arabinofuranosidase }\end{array}$ & 14 & - & 12 & 12 \\
\hline $\mathrm{GH} 4$ & a-galactosidase & - & 1 & 38 & 39 \\
\hline $\mathrm{GH} 10$ & Endo-1,4- $\beta$-xylanase & - & 1 & - & 1 \\
\hline $\mathrm{GH} 11$ & Endo- $\beta-1,4$-xylanase & - & - & 1 & 1 \\
\hline $\mathrm{GH} 16$ & Xyloglucanase & 1 & 2 & 2 & 4 \\
\hline $\mathrm{GH} 27$ & a-galactosidase & 5 & - & - & - \\
\hline $\mathrm{GH} 29$ & a-L-fucosidase & 18 & 2 & - & 2 \\
\hline $\mathrm{GH} 31$ & a-galactosidase; a-xylosidase & - & 6 & 23 & 29 \\
\hline GH35 & $\beta$-galactosidase & 12 & - & - & - \\
\hline GH36 & a-galactosidase & - & 3 & 2 & 5 \\
\hline GH39 & $\beta$-xylosidase & - & - & 3 & 3 \\
\hline $\mathrm{GH} 42$ & $\beta$-galactosidase & - & 7 & 2 & 9 \\
\hline $\mathrm{GH} 43$ & $\begin{array}{l}\text { ß-xylosidase; } \text { a-L- } \\
\text { arabinofuranosidase; } \\
\text { arabinanase; xylanase }\end{array}$ & - & 2 & 15 & 17 \\
\hline GH53 & Endo- $\beta-1,4-$ galactanase & - & - & 2 & 2 \\
\hline GH57 & a-galactosidase & - & 2 & - & 2 \\
\hline $\mathrm{GH} 113$ & $\beta$-mannanase & - & 2 & 3 & 5 \\
\hline $\mathrm{GH} 116$ & $\beta$-xylosidase & 2 & - & - & - \\
\hline $\mathrm{GH} 120$ & $\beta$-xylosidase & 2 & - & 1 & 1 \\
\hline GH134 & Endo- $\beta-1,4-m a n n a n a s e$ & - & - & 3 & 3 \\
\hline \multicolumn{2}{|c|}{ Hemicellulases and/or cellulases } & 65 & 42 & 114 & 156 \\
\hline $\mathrm{GH} 1$ & $\begin{array}{l}\beta \text {-glucosidase; } \beta \text {-galactosidase; } \\
\text { exo- } \beta-1,4 \text {-glucanase; } \beta \text { - } \\
\text { mannosidase; } \beta \text {-xylosidase }\end{array}$ & - & 4 & 53 & 57 \\
\hline $\mathrm{GH} 3$ & $\begin{array}{l}\beta \text {-glucosidase; exo- } \beta-1 \text {, } \\
\text { 4-glucanase; xylan 1,4- } \beta \text {-xylosi } \\
\text { dase; } a-L \text {-arabinofuranosidase }\end{array}$ & - & 15 & 28 & 43 \\
\hline
\end{tabular}

Table 3 List of CAZymes implicated in lignocellulose degradation in the A. vulgare holobiont. Presented are the total numbers of CAZy modules for each family in the host reference transcriptome and in the metagenome assemblies (Continued)

\begin{tabular}{|c|c|c|c|c|c|}
\hline \multirow[t]{2}{*}{ CAZy family } & \multirow[t]{2}{*}{ Known activities } & \multirow[t]{2}{*}{ Host } & \multicolumn{3}{|c|}{$\begin{array}{l}\text { Metagenome } \\
\text { assemblies }\end{array}$} \\
\hline & & & Field & Lab & Total \\
\hline GH5 & 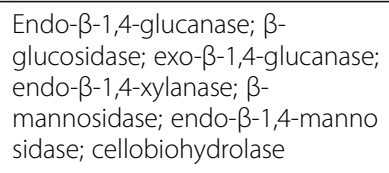 & 11 & 14 & 5 & 19 \\
\hline $\mathrm{GH} 8$ & $\begin{array}{l}\text { Endo- } \beta-1,4-\text { glucanase; endo- } 1 \text {, } \\
4-\beta \text {-xylanase }\end{array}$ & - & - & 21 & 21 \\
\hline $\mathrm{GH} 9$ & $\begin{array}{l}\text { Endo- } \beta-1,4-\text { glucanase; } \beta \text { - } \\
\text { glucosidase; exo- } \beta-1,4-\text { glucanase; } \\
\text { cellobiohydrolase }\end{array}$ & 14 & - & 2 & 2 \\
\hline $\mathrm{GH} 30$ & $\begin{array}{l}\beta \text {-glucosidase; endo- } \beta-1, \\
\text { 4-xylanase; } \beta \text {-xylosidase }\end{array}$ & 39 & 6 & - & 6 \\
\hline GH51 & $\begin{array}{l}\text { Endo- } \beta \text {-1,4-glucanase; } \\
\text { endo- } \beta-1,4 \text {-xylanase; } \\
\beta \text {-glucosidase; } \beta \text {-xylosidase; } \\
\text { a-L-arabinofuranosidase }\end{array}$ & - & 1 & - & 1 \\
\hline $\mathrm{GH} 74$ & $\begin{array}{l}\text { Endo- } \beta-1,4-\text {-glucanase; } \\
\text { xyloglucanase }\end{array}$ & 1 & 2 & 2 & 4 \\
\hline GH94 & Cellobiose phosphorylase & - & - & 3 & 3 \\
\hline \multicolumn{2}{|c|}{ Lignocellulose-binding modules } & 57 & 519 & 356 & 875 \\
\hline CBM1 & Cellulose-binding & - & - & 2 & 2 \\
\hline $\mathrm{CBM} 2$ & Cellulose and xylan binding & - & 4 & 2 & 6 \\
\hline CBM3 & Cellulose-binding & - & 3 & 1 & 4 \\
\hline CBM4 & $\begin{array}{l}\text { Cellulose, xylan, } \beta-1,3-\text { glucan, } \\
\text { and } \beta-1,3-1,4-\text { glucan binding }\end{array}$ & - & 1 & 1 & 2 \\
\hline CBM6 & Cellulose-binding & - & 3 & 1 & 4 \\
\hline CBM8 & Cellulose-binding & - & - & 1 & 1 \\
\hline CBM10 & Cellulose-binding & - & 1 & 1 & 2 \\
\hline CBM13 & Xylan-binding & 16 & 3 & 1 & 4 \\
\hline CBM15 & $\begin{array}{l}\text { Xylan and xylooligosaccharides } \\
\text { binding }\end{array}$ & - & 2 & - & 2 \\
\hline CBM16 & $\begin{array}{l}\text { Cellulose and glucomannan } \\
\text { binding }\end{array}$ & - & - & 2 & 2 \\
\hline CBM22 & Xylan-binding & - & 2 & 2 & 4 \\
\hline CBM23 & Mannan-binding & 1 & 1 & - & 1 \\
\hline CBM27 & Mannan-binding & - & 1 & 2 & 3 \\
\hline CBM29 & $\begin{array}{l}\text { Mannan and glucomannan } \\
\text { binding }\end{array}$ & - & 2 & 5 & 7 \\
\hline CBM30 & Cellulose-binding & - & 6 & 5 & 11 \\
\hline CBM31 & $\beta-1,3$-xylan-binding & 1 & 4 & 5 & 9 \\
\hline CBM32 & Galactose-binding & 19 & 9 & 42 & 51 \\
\hline CBM35 & $\begin{array}{l}\text { Xylan, mannans and } \beta \text {-galactan } \\
\text { binding }\end{array}$ & - & 4 & 2 & 6 \\
\hline CBM36 & $\begin{array}{l}\text { Xylans and xylooligosaccharides } \\
\text { binding }\end{array}$ & - & 4 & 2 & 6 \\
\hline CBM37 & Cellulose and xylan binding & 8 & 3 & 8 & 11 \\
\hline CBM39 & $\beta-1,3$-glucan-binding & - & 4 & 3 & 7 \\
\hline
\end{tabular}


Table 3 List of CAZymes implicated in lignocellulose degradation in the A. vulgare holobiont. Presented are the total numbers of CAZy modules for each family in the host reference transcriptome and in the metagenome assemblies (Continued)

\begin{tabular}{|c|c|c|c|c|c|}
\hline \multirow[t]{2}{*}{ CAZy family } & \multirow[t]{2}{*}{ Known activities } & \multirow[t]{2}{*}{ Host } & \multicolumn{3}{|c|}{$\begin{array}{l}\text { Metagenome } \\
\text { assemblies }\end{array}$} \\
\hline & & & Field & Lab & Total \\
\hline CBM42 & Arabinofuranose-binding & - & 1 & 1 & 2 \\
\hline CBM43 & $\beta$-1,3-glucan-binding & - & 4 & 1 & 5 \\
\hline CBM44 & Cellulose and xyloglucan binding & - & 8 & 8 & 16 \\
\hline CBM46 & Cellulose-binding & - & 2 & 4 & 6 \\
\hline CBM47 & Fucose-binding & 8 & 401 & 228 & 629 \\
\hline CBM49 & Crystalline cellulose binding & - & 5 & 4 & 9 \\
\hline CBM51 & Galactose-binding & - & 4 & 1 & 5 \\
\hline CBM54 & Xylan-binding & - & 6 & 1 & 7 \\
\hline CBM56 & $\beta$-1,3-glucan-binding & 1 & - & 1 & 1 \\
\hline CBM62 & $\begin{array}{l}\text { Xyloglucan, arabinogalactan, and } \\
\text { galactomannan binding }\end{array}$ & - & 1 & - & 1 \\
\hline CBM63 & Cellulose-binding & - & 2 & 2 & 4 \\
\hline CBM64 & Cellulose-binding & - & 5 & 2 & 7 \\
\hline CBM67 & L-rhamnose-binding & 3 & 4 & 6 & 10 \\
\hline CBM72 & $\begin{array}{l}\text { Cellulose, } \beta \text {-1,3-glucans, xylan, } \\
\text { and } \beta \text {-mannan binding }\end{array}$ & - & 5 & 2 & 7 \\
\hline CBM76 & $\begin{array}{l}\text { Xyloglucan, glucomannan, } \\
\text { and } \beta \text {-glucan binding }\end{array}$ & - & 1 & 1 & 2 \\
\hline CBM78 & $\begin{array}{l}\beta-1,4-g l u c a n s \text { and xyloglucan } \\
\text { binding }\end{array}$ & - & 1 & 2 & 3 \\
\hline CBM79 & $\beta$-glucans-binding & - & 3 & - & 3 \\
\hline CBM80 & $\begin{array}{l}\text { Xyloglucan, glucomannan, } \\
\text { and galactomannan binding }\end{array}$ & - & 9 & 4 & 13 \\
\hline
\end{tabular}

GH29 was specific to the tissue samples, and GH30 was found in the hindgut and the tissue samples. Concerning the lignocellulose-binding modules found in the microbiome, 40.1\% (351 modules) were identified in the hindgut, 36.5\% (319 modules) were identified in the tissue samples, and $23.4 \%$ (205 modules) in the gut content (Table 4). Twenty-one different lignocellulose-binding module families were found in the gut content and 5 of these were not detected in the microbiota from host tissues (CBM13, CBM16, CBM22, CBM51, CBM56). Twenty-seven families were found in the tissue samples (3 of which exclusively in this sample type: CBM1, CBM62, CBM8), and 29 families were found in the hindgut, again 3 of them being specific to this tissue (CBM10, CBM23, CBM42).

Three AA families known as lignin modifying enzymes (LMEs) were found in the A. vulgare holobiont (Table 3, Fig. 1): laccases (AA1; EC 1.10.3.2) and cellobiose dehydrogenases (AA3; EC 1.1.99.18) were identified in the host, and peroxidases (AA2; EC 1.11.1.13) were identified in the microbiome (Fig. 2).
Table 4 Tissue distribution of CAZymes implicated in lignocellulose degradation in the metagenomes. Presented are the total numbers of CAZy modules for each family per sample type

\begin{tabular}{llll}
\hline CAZymes & Gut content & Hindgut & Tissue samples \\
\hline Lignin-modifying enzymes & 28 & 0 & 1 \\
Hemicellulases & 252 & 35 & 34 \\
Hemicellulases and/or cellulases & 129 & 8 & 19 \\
Lignocellulose-binding modules & 205 & 351 & 319
\end{tabular}

Cellulases are commonly classified as GH families. Nine GH families known to exhibit cellulase activity were identified in the $A$. vulgare holobiont (Table 3, Fig. 1). They were all present in the microbiome and four were also found in the host (GH5, GH9, GH30, GH74). Among them, two GH families (GH1 and GH3) were identified as glucosidases (EC 3.2.1.21) in the microbiome by Hotpep (Fig. 2), and another two were identified as endoglucanases (EC 3.2.1.4) in the microbiome and in the host ( $\mathrm{GH} 8$ and $\mathrm{GH} 9$, respectively). Furthermore, genes encoding cellobiose phosphorylase (GH94; EC 2.4.1.20) were found in the microbiome.

Hemicellulases were highly represented in the $A$. vulgare holobiont, corresponding to many $\mathrm{CE}$ and $\mathrm{GH}$ families. Thirty-two were identified in the microbiome and 15 in the host (Table 3, Fig. 1). All hemicellulases found in the host transcriptome except for GH116, GH27, and GH35 were also present in the microbiome. Among them, Hotpep identified two debranching enzymes, seven exo-hemicellulases, and one endo-hemicellulase (Fig. 2).

The $A$. vulgare holobiont presented a high diversity of lignocellulose-binding modules (Table 3 ). The majority (93.9\%) was present in the microbiome; 39 CBMs found in the microbiome are known to bind diverse components present in lignocellulose, while only 8 lignocellulose-binding module families were found in the host. Furthermore, all CBM families found in the host were also present in the microbiome.

The expression of lignocellulose-degrading CAZymes identified in the host transcriptome was confirmed by RT-qPCR (Fig. 3). Specifically, one representative gene with the highest RPKM value was selected for each CAZy family identified in the host transcriptome and its expression quantified in digestive tissues (caeca, hindgut, gut content) and non-digestive tissues. All selected genes were expressed in vivo except for GH16, which we were not able to amplify. Most genes encoding glycoside hydrolases (excepting GH74, GH116, GH120), including cellulases and hemicellulases, were specifically expressed in the caeca, whereas genes encoding AA3 (LME) and CE4 (debranching enzyme) were highly expressed specifically in the hindgut. Other selected genes (GH74, GH116, GH120, CE1, and CE12) were ubiquitously expressed in host tissues but not in the gut content. 


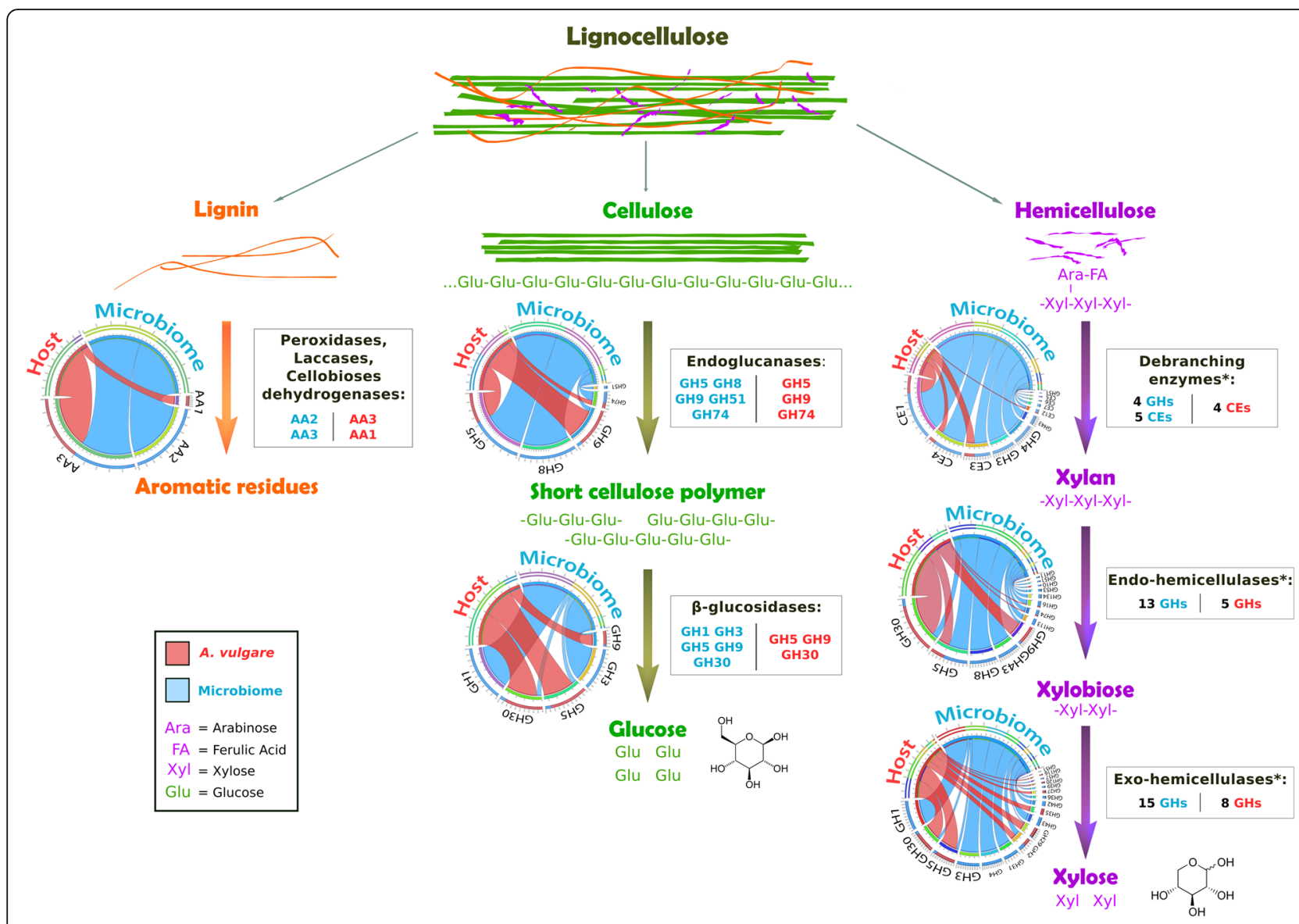

Fig. 1 Model for lignocellulose degradation in the A. vulgare holobiont. Diagrams represent the CAZy families contributed by the host (red) and the microbiome (blue). (I) Lignin would be partially degraded to release cellulose and hemicellulose. (II) Cellulose would be degraded by the action of endoglucanases and $\beta$-glucosidases. A high number of $\beta$-glucosidases and mechanical fragmentation by $A$. vulgare could compensate for the lack of exoglucanases. (III) The A. vulgare holobiont could degrade most types of hemicellulose due to the high diversity of Debranching enzymes* (CE1, CE3, CE4, CE5, CE6, CE7, CE12, GH3, GH4, GH43, GH51), Endo-hemicellulases* (GH5, GH8, GH9, GH10, GH11, GH16, GH30, GH43, GH51, GH53, GH74, GH113, GH128, GH134), and Exo-hemicellulases* (GH1, GH2, GH3, GH4, GH5, GH27, GH29, GH30, GH31, GH35, GH36, GH39, GH42, GH43, GH51, GH57, GH116, GH120)

Finally, CE3 was expressed in all host tissues as well as the gut content. Given that GH74, GH116, and GH120 host transcripts were expressed in all tissues and that they were not identified as lignocellulose-degrading CAZymes by Hotpep (Additional file 6: Table S4), they were excluded from the rest of the study.

\section{Microbiota associated with lignocellulose degradation}

In order to assign genes annotated as lignocellulose-degrading CAZymes and lignocellulose-binding modules in the microbiome to prokaryotic taxa, these genes were compared against the non-redundant protein database by BLASTp searches and the results were imported into MEGAN6 [70]. This allowed the taxonomic identification of 438 genes, corresponding to $95.4 \%$ of all prokaryotic genes encoding lignocellulose-degrading CAZymes in the metagenome assemblies. Concerning the lignocellulose-binding modules, only $8.9 \%$ (78 genes) of these modules were taxonomically assigned to prokaryotic genes. Most lignocellulose-degrading genes and lignocellulose-binding module genes were associated with the bacterial phyla Proteobacteria and Actinobacteria (Table 5). The remaining bacterial genes were distributed among the Bacteroidetes, Firmicutes, and several candidate phyla. Several lignocellulose-degrading genes were also assigned to archaea belonging to the phylum Thaumarchaeota (Table 5).

The lignocellulose-degrading microbiotas from laboratory lineages (consisting of Wolbachia-infected females, uninfected females and males) were highly similar (Fig. 4a). In contrast, the microbiotas of males and females from the field were different, and this was due to the high abundance of Rickettsiella (Coxiellaceae family) in females, while the other bacterial families were similarly abundant in both sexes (Fig. 4a). Therefore, samples from both sexes and with different Wolbachia infection status in the two populations were grouped for further analyses (Fig. 4b). 


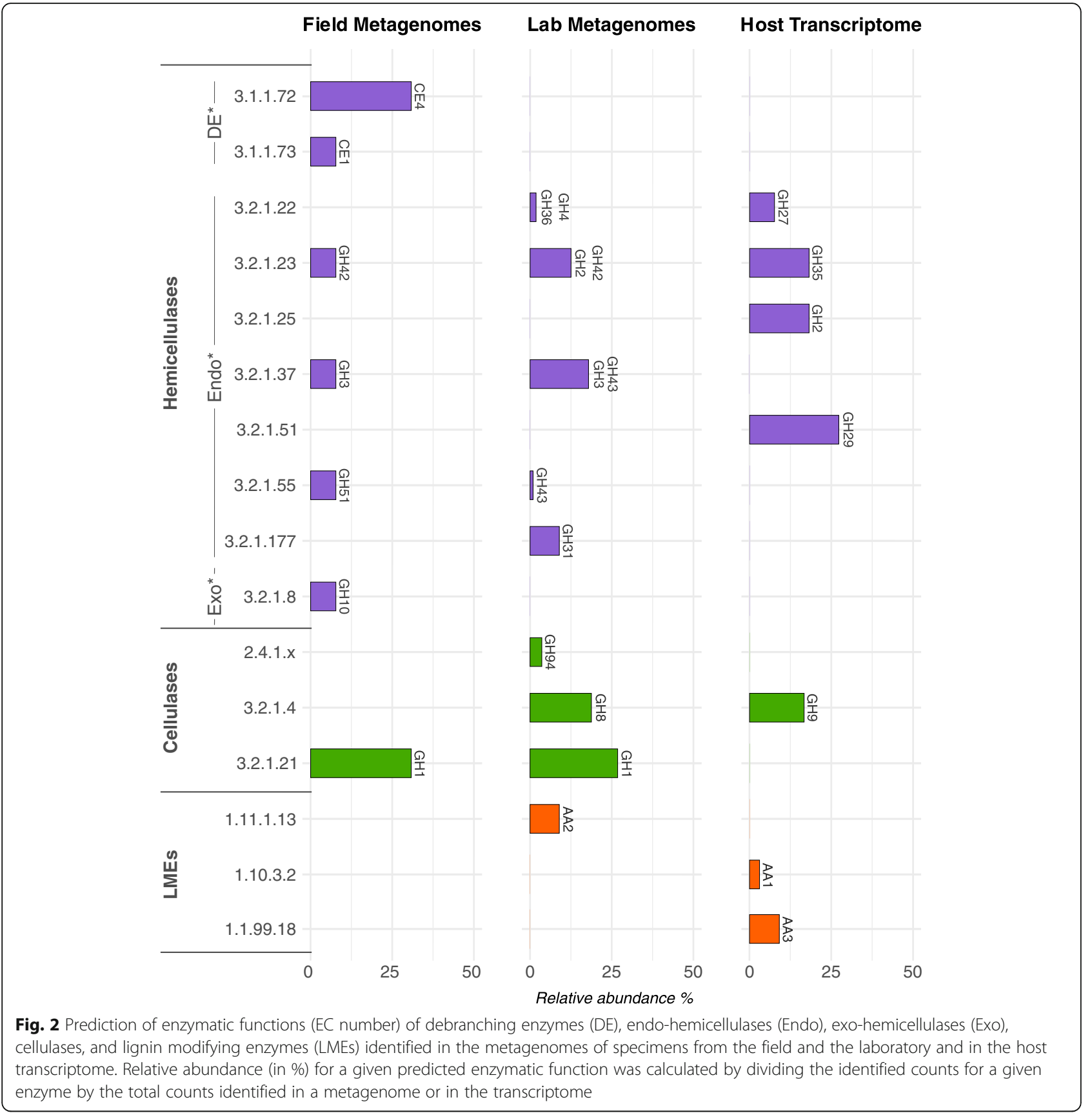

There was a clear difference in the contribution of different microbial taxa to lignocellulose degradation between field and lab-derived isopods (Figs. 4 and 5). Enterobacteriaceae and Vibrionaceae were the bacterial families with the highest contribution of lignocellulose-degrading genes in animals from laboratory lineages $(74.1 \%$ of laboratory lignocellulose-degrading genes), whereas Coxiellaceae, Nitrososphaeraceae, Microbacteriaceae, and Anaplasmataceae contributed more lignocellulose-degrading genes in isopods from the field population $(49.7 \%$ of field lignocellulose-degrading genes). In particular, the genera
Vibrio, Kluyvera, and Enterobacter contributed most hemicellulases and cellulases in specimens from the laboratory, whereas Vibrio, Buttiauxella, and Halomonas contributed most LMEs (87\% of the bacterial genes encoding LMEs) (Fig. 5a). In isopods from the field, the bacteria Rickettsiella, Wolbachia, Microbacterium, and the archaea Candidatus Nitrosocosmicus and Nitrososphaera contributed $72 \%$ of the microbial genes encoding hemicellulases (Fig. 5b). Similarly, the bacteria Rickettsiella, Microbacterium, Cellulosimicrobium, and the archaea Candidatus Nitrosocosmicus were the microorganisms most frequently associated 


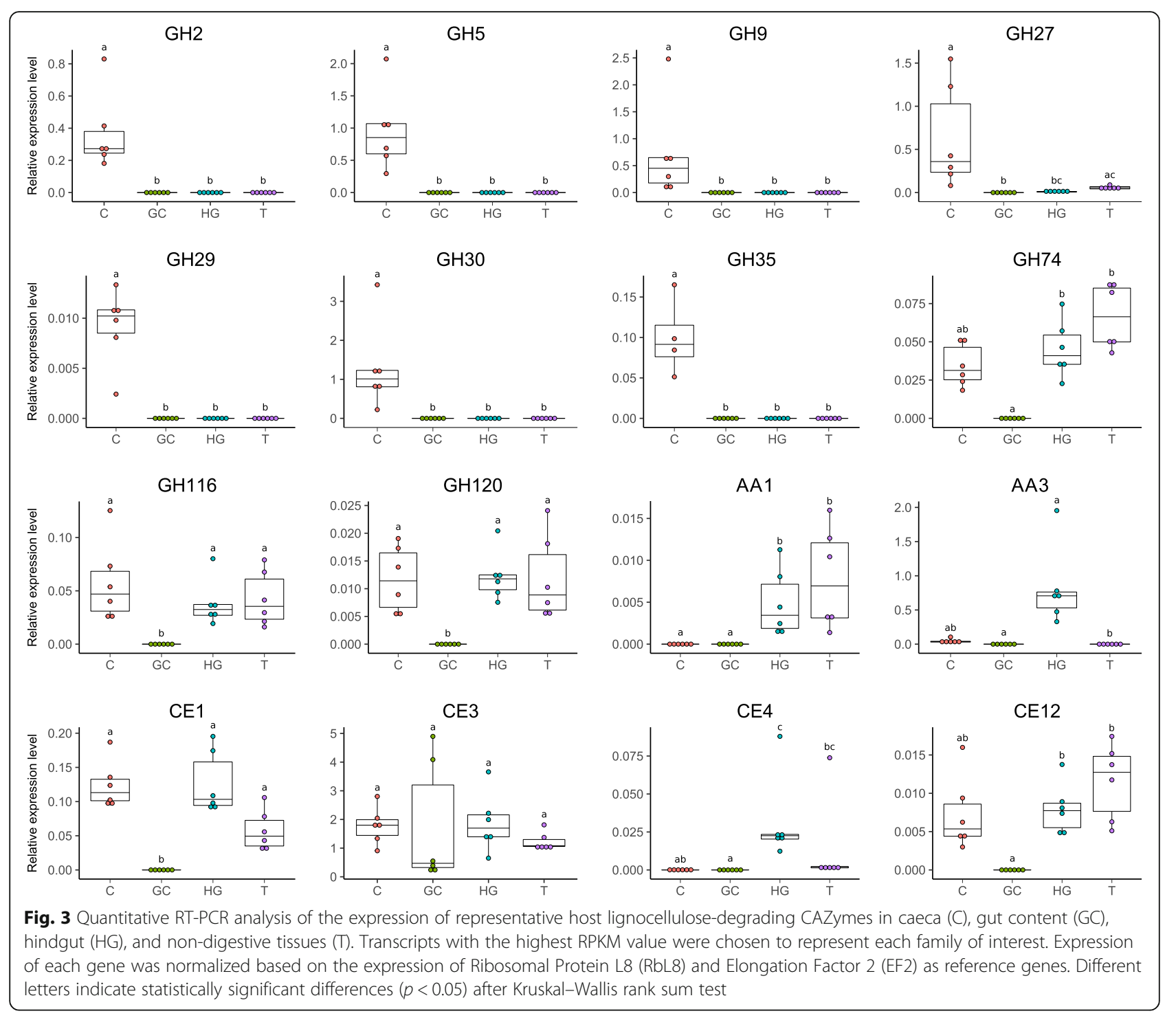

Table 5 Prokaryotic phyla associated with genes contributing to lignocellulose degradation in the isopod metagenomes depending on host origin. Presented are the total numbers of CAZymes in metagenome assemblies

\begin{tabular}{|c|c|c|c|c|}
\hline \multirow[t]{2}{*}{ Phylum } & \multicolumn{2}{|c|}{ Lignocellulose-degrading genes } & \multicolumn{2}{|c|}{ Lignocellulose-binding module genes } \\
\hline & Field & Lab & Field & Lab \\
\hline Proteobacteria & 38 & 321 & 14 & 24 \\
\hline Bacteroidetes & 2 & 1 & 2 & - \\
\hline Actinobacteria & 30 & - & 16 & 3 \\
\hline Firmicutes & 1 & - & - & - \\
\hline Bacteria candidate phyla & 3 & - & 3 & - \\
\hline Thaumarchaeota & 29 & - & 2 & - \\
\hline Unclassified bacteria & 3 & 10 & 3 & 11 \\
\hline
\end{tabular}




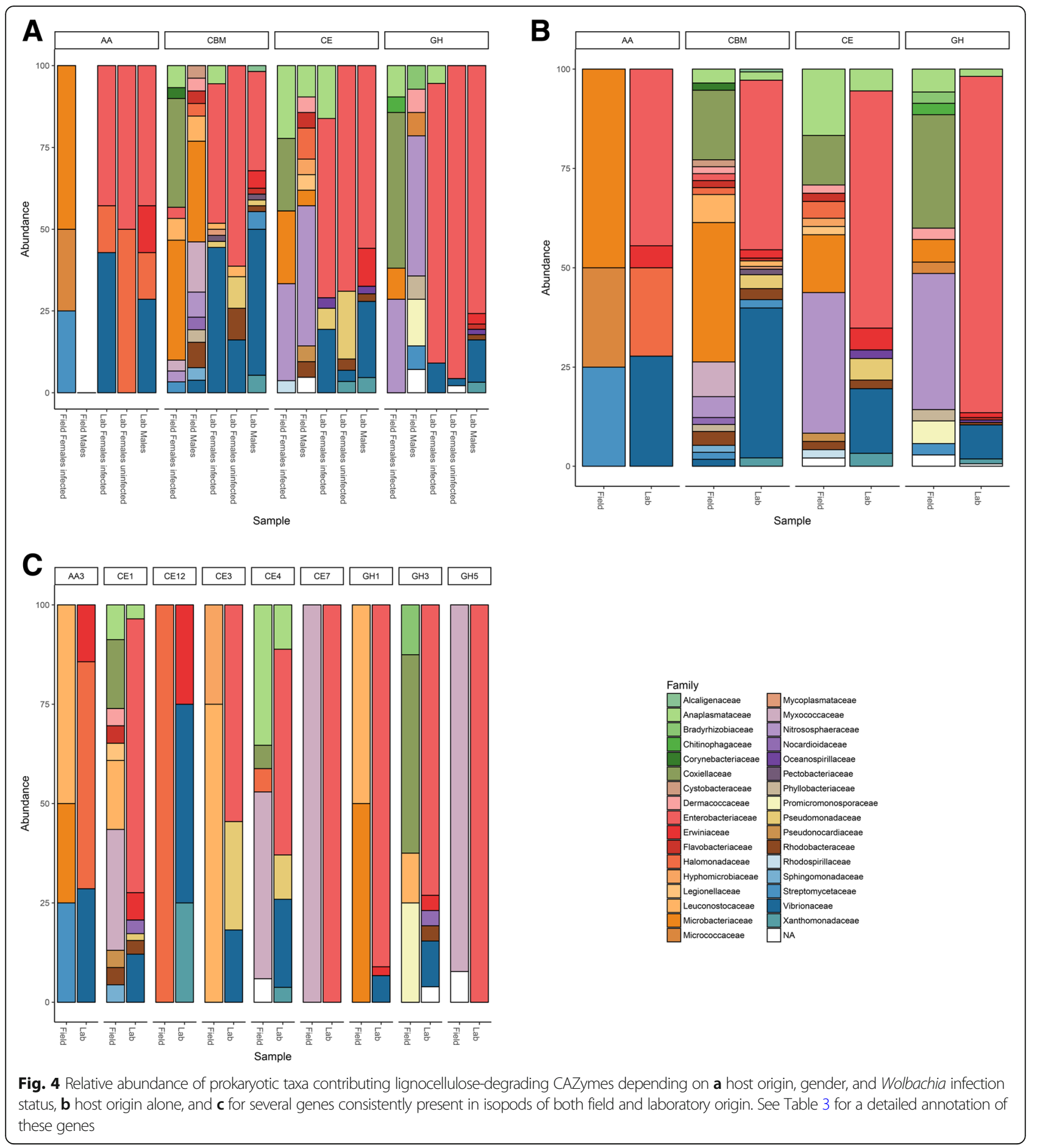

with cellulases $(77 \%$ of prokaryotic genes encoding cellulases in isopods from the field) (Fig. 5b). Finally, Streptomyces, Microbacterium, Arthrobacter, and Leucobacter were associated with all genes encoding LMEs in isopods from the field.

Among the 78 genes encoding lignocellulose-binding modules that were assigned to prokaryotes, the bacterial genera Microbacterium and Myxococcus contributed most genes in isopods from the field (44\%), while Kluyvera, Vibrio, and Photobacterium represented $65 \%$ of prokaryotes associated with lignocellulose-binding modules in laboratory samples (Fig. 5c).

Given that fungi play an important role in lignocellulose degradation in various ecosystems, their presence in 


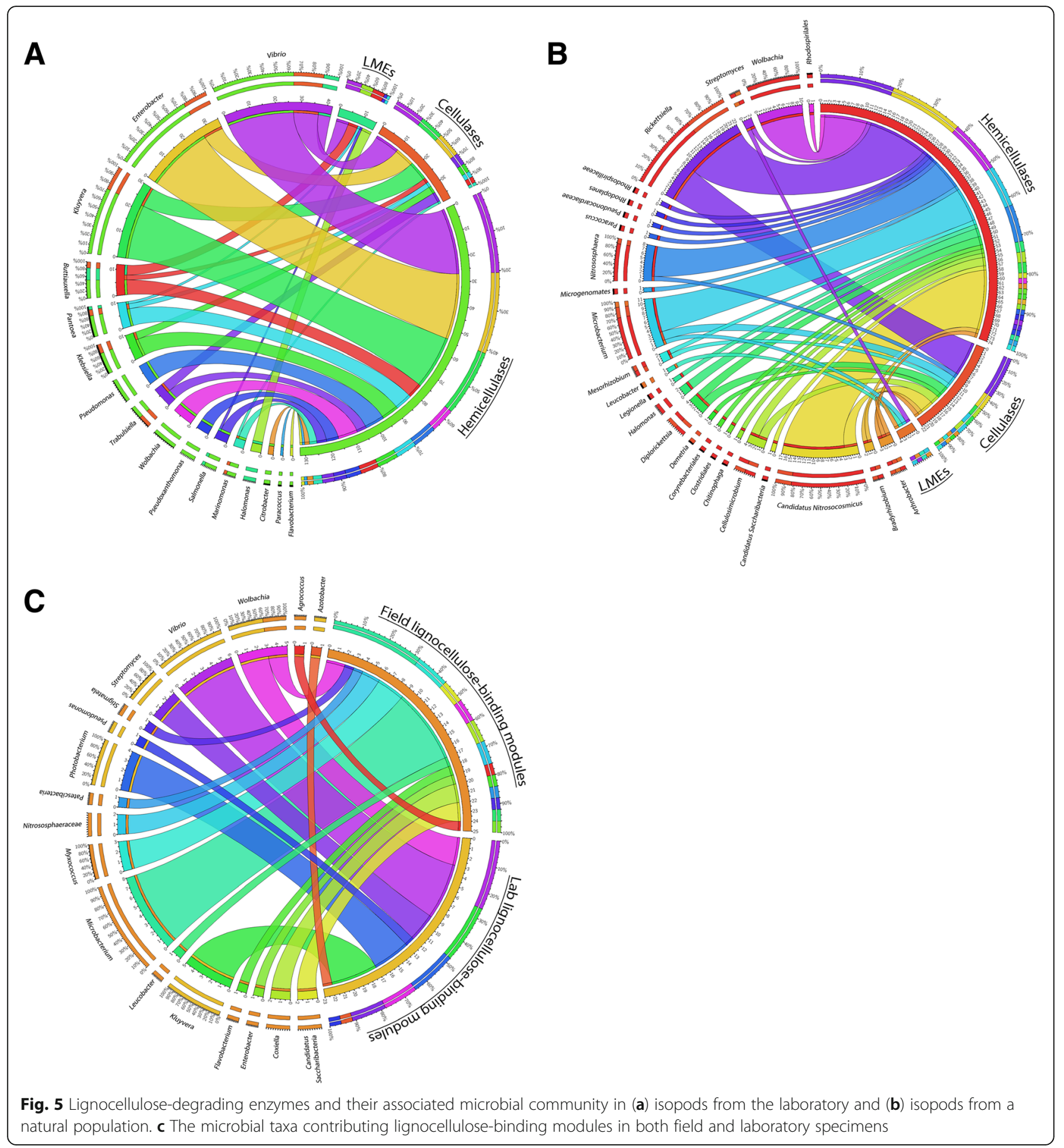

the metagenomes of $A$. vulgare was also expected. Eleven fungal genes encoding lignocellulose-degrading CAZymes were detected in only one metagenome (the gut content of Wolbachia-free females from the laboratory lineages), and they were all affiliated with Aureobasidium pullulans, a ubiquitous fungus that can be found in various ecosystems and in association with plants [77]. The low number of lignocellulose-degrading CAZymes identified from fungi may be due to the prokaryotic enrichment procedure used for the construction of the metagenomic libraries.

Although some CAZymes were specific to a particular sample type (Table 3), overall there was a high functional redundancy in enzymatic activities between microbiotas from lab- and field-derived isopods, indicating that several CAZy families could have the same enzymatic activity. Furthermore, all shared CAZy families were associated with different microbiotas 
depending on host origin (Fig. 4c). Thus, different microbial communities would still provide the same enzymatic activities for lignocellulose degradation.

\section{Discussion}

This study represents the first investigation of the complete enzyme repertoire involved in lignocellulose degradation in a terrestrial isopod. The construction of a highly complete host transcriptome combined with a functional characterization of the microbiome of $\mathrm{A}$. vulgare via shotgun metagenomics allowed the identification of both endogenous and microbial enzymes degrading lignocellulose. A. vulgare of both laboratory and field origin as well as several host tissues and the gut content were included, with the aim to assess potential impacts of the environment and diet. We produced a highly complete reference transcriptome of $A$. vulgare (95.7\% of complete genes identified from BUSCO database) and 15 metagenome assemblies allowing a deep investigation of the $A$. vulgare microbiome. Many CAZymes belonging to 231 families were detected in the A. vulgare holobiont, placing this species at the same level as termites in terms of CAZyme diversity [78, 79]. Among these, we identified a high diversity of lignocellulose-degrading enzymes, including cellulases, hemicellulases, and LMEs.

The synergistic action of several specific CAZymes is needed to completely degrade lignocellulose. Among CAZy classes, several families are known to be particularly implicated in lignocellulose degradation: glycoside hydrolase families (GHs), carbohydrate esterase families (CEs), and auxiliary activity families (AAs) [65]. Prior to cellulose and hemicellulose decomposition, the complex heteropolymer lignin has to be degraded. Lignin is the most difficult component to degrade in lignocellulose because of its complex and irregular structure, which requires enzymes (LMEs classified in AA families [12, 65]) with less specificity than cellulases and hemicellulases [80]. To date, the lignin degradation mechanism in $A$. vulgare is not well understood: although Zimmer and Brune [81] showed that the isopod gut presents adequate conditions for aerobic and oxidative digestive processes that are needed for lignin degradation, lignin seems to be only partially degraded in isopods [3, 30, 34, 82, 83]. While LMEs are uncommon in animals, we identified laccases (AA1) and cellobiose dehydrogenases (AA3) in the $A$. vulgare transcriptome. Our results further demonstrated that endogenous LMEs are expressed in the $A$. vulgare hindgut, which agrees with termites where endogenous laccases are expressed throughout the whole gut [23]. The absence of LME expression in the caeca is probably due to the too low oxygen level in this tissue [46]. Laccases seem to be expressed exclusively by $A$. vulgare itself, while the microbiota provides additional cellobiose dehydrogenases (AA3) and peroxidases (AA2). Although the role of endogenous laccases in lignin degradation is well characterized in termites [23, 24, 27], we show here that a laccase gene (belonging to the AA1 family) was also expressed in A. vulgare non-digestive tissues, suggesting a role beyond lignin degradation. Indeed, laccases can also be involved in both the melanization and sclerotization of the cuticular layers, as shown in other arthropods [84]. Cellobiose dehydrogenases were found in both the host and the microbiome, but their exact role in lignocellulose degradation is still unclear, with some evidence for their implication in both cellulose and lignin degradation [85, 86]. Our results provide new insights into lignin degradation in terrestrial isopods, demonstrating that a cooperation between members of the $A$. vulgare holobiont could indeed result in the partial modification of lignin and the release of cellulose and hemicellulose. As previously demonstrated in termites [23, 87, 88], this could be achieved in a cooperative manner in different parts of the digestive system.

Once lignin is degraded, enzymes can attack cellulose and hemicellulose from plant biomass. Cellulose is the most abundant component of lignocellulose [19]. Its degradation is best characterized in fungi where three types of enzyme are required for the process: endoglucanases, $\beta$-glucosidases, and cellobiohydrolases (exoglucanases) [89]. Our comparative analysis of transcriptomic and metagenomic datasets suggests that $A$. vulgare could digest cellulose in cooperation with its microbiota, similar to termites [23-25, 27]. Previous studies had already characterized endogenous endoglucanases in isopods, but not in their microbiome [47-49]. Endoglucanases annotated in the $A$. vulgare reference transcriptome were affiliated with the GH5 and GH9 families. The GH9 family comprises the most widespread endogenous animal endoglucanases, whereas GH5 is less common [90]. Endoglucanases were also found in great abundance in the microbiome of $A$. vulgare, belonging to the GH5, GH8, GH9, GH51, and GH74 families. Whereas endoglucanases are widespread in animals, $\beta$-glucosidase are less common [90]. Among the CAZy families known as $\beta$-glucosidases identified in the $A$. vulgare reference transcriptome (GH5, GH9, and GH30) and in the microbiome (GH1 and GH3), only GH1 genes were functionally predicted as $\beta$-glucosidases in the microbiome. The third type of cellulolytic enzymes, cellobiohydrolases are uncommon in animals and are usually classified as GH6, GH7, and GH48 [19, 65, 78, 91]. Accordingly, there was no clear evidence for the presence of cellobiohydrolases in the A. vulgare holobiont. However, Allardyce et al. [92] proposed a model for cellulose hydrolysis involving only endoglucanases and $\beta$-glucosidases in the land crab Gecarcoidea natalis. As in several insects, the lack of 
cellobiohydrolases could thus be compensated by the high number of endoglucanases, despite the low activity of these enzymes against crystalline cellulose [93]. Furthermore, mechanical fragmentation of the food into small particles by mandibles and proventriculus [94] facilitates enzyme access to lignocellulose [19]. The identification of host endoglucanases in the caeca of Porcellio scaber, the common rough woodlouse [48], shed doubts on the previous hypothesis [95] that cellulose degradation was achieved by endosymbiotic bacteria in the caeca. Zimmer and Topp [95] showed that cellulase activity was high in caeca and hindgut, but they could not clearly attribute this activity to the microbiota, the isopod itself, or both. Our gene expression analysis reveals that the isopod caeca represent the major site of transcription of endogenous host cellulases, while very few microbial cellulases were found in caeca. Indeed, the majority of microbial cellulases were found in the gut content. These results suggest a two-step collaboration for cellulose digestion, where the pill bug primarily hydrolyses cellulose with its own endoglucanases produced in the caeca and the gut microbiota completes cellulose digestion with other endoglucanases and $\beta$-glucosidases in the hindgut as in termites [21, 23].

Hemicellulases have been previously characterized in several crustaceans [96-98], but not yet in terrestrial isopods. The main chain of hemicellulose is composed of xylose, glucose, and mannose, which is often branched with arabinose, galactose, and other acidic sugars. Therefore, the degradation of hemicellulose requires a larger enzymatic arsenal than the degradation of cellulose. Our metagenome and transcriptome data revealed that the gut microbiota and the host produce many hemicellulases, again suggesting a close cooperation between members of the $A$. vulgare holobiont in hemicellulose degradation. We identified 31 hemicellulase families in the $A$. vulgare holobiont, which could degrade most types of hemicellulose. Based on our data, the microbiota would play the major role in hemicellulose degradation, providing more than twice as many hemicellulose families than the host. The comparative analysis of the hemicellulases from the host and the microbiome further revealed a high level of functional redundancy with multiple predicted xylanases, arabinases, mannanases, and xyloglucanases. As observed in other studies [4], this redundancy may indicate an enzymatic synergism between $A$. vulgare and its microbiome, which might degrade hemicellulose in a cooperative manner.

In addition, we identified the microbial taxa contributing genes potentially involved in lignocellulose degradation in $A$. vulgare. Previous work had already demonstrated a high bacterial diversity in all major tissues of $A$. vulgare, with distinct bacterial communities between individuals originating from the field or from the laboratory $[42,51,52]$. Here, we show that despite their different taxonomic compositions, these bacterial communities are similar in their repertoire of lignocellulose-degrading CAZymes, resulting in a high functional redundancy for lignocellulose degradation between field and laboratory-derived isopods. Indeed, many CAZy families can act on multiple substrates and many enzymatic activities can be provided by several CAZy families $[65,99]$. While bacteria such as Fibrobacteres, Bacteroidetes, and Firmicutes abundantly colonize the hindgut of termites [28, 100], the composition of the bacterial communities associated with lignocellulose-degradation in $A$. vulgare was significantly different. Being dominated by Proteobacteria and Actinobacteria, the lignocellulose-degrading microbiota of $A$. vulgare was in fact more similar to the gut microbiota of xylophagous beetles [101]. Proteobacteria were particularly dominant in $A$. vulgare from laboratory lineages. Among them, Enterobacteriaceae (genera Klebsiella, Enterobacter, and Buttiauxella) contributed most lignocellulose-degrading CAZymes. These bacteria are common in arthropods [102] and known to have various metabolic capabilities, such as contributing to nitrogen intake and lignocellulose degradation in insects [101]. The second largest contribution of lignocellulose-degrading CAZymes in A. vulgare from laboratory lineages was provided by members of the Vibrionaceae, also Proteobacteria. These bacteria are best known for their pathogenicity, and to date, there is only one study reporting cellulases in the Vibrio genus [103]. Halomonas spp. (Halomonadaceae) are also of interest, since they represent one of the most abundant bacterial genera within the A. vulgare microbiome [42, 51, 52].Their genomes possess several genes encoding LMEs, and they are known to contribute to lignin degradation [104]. Accordingly, they were identified as major contributors of LMEs in isopods from laboratory lineages. Among the bacteria associated with genes encoding lignocellulose-degrading CAZymes in isopods from the field, several Actinobacteria such as Microbacterium spp. (Microbacteriaceae) and Cellulosimicrobium spp. (Promicromonosporaceae) have previously been shown to possess cellulose and hemicellulose-degrading activities [105-107]. Similarly, bacteria associated with genes encoding LMEs in isopods from the field were already known for their lignin-degrading activity: Arthrobacter spp. (Micrococcaceae), Streptomyces spp. (Streptomycetaceae), Microbacterium spp., and Leucobacter spp. (Microbacteriaceae) [108, 109]. Our results further showed that Archaea might also contribute to lignocellulose degradation in $A$. vulgare: we identified genes encoding cellulases and hemicellulases from Candidatus Nitrosocosmicus and Nitrososphaera, two genera of the Nitrososphaeraceae family. To date, no role in lignocellulose-degradation has 
been demonstrated for these archaea, but it has been suggested that they might contribute to nitrification in fertilized soils and oxidize ammonia [110, 111].

Several lignocellulose-degrading CAZymes were associated with two unexpected bacteria, Rickettsiella and Wolbachia. Indeed, many hemicellulases and cellulases were identified as belonging to the genus Rickettsiella (Coxiellaceae) in A. vulgare from the field. Rickettsiella spp. are mainly known as arthropod pathogens (reviewed in [112]) or mutualists [113], and until now, no lignocellulose-degrading activity has been demonstrated for these bacteria. In addition, several acetyl xylan esterases (endo-hemicellulases) belonging to the CE4 family were associated with Wolbachia spp. (Rickettsiaceae) in isopods harboring feminizing Wolbachia strains, independent of host origin. The CE4 family comprises CAZymes which have many other catalytic activities, such as chitin deacetylase, chitooligosaccharide deacetylase, and peptidoglycan deacetylase [65]. Therefore, CE4 enzymes do not necessarily contribute to hemicellulose degradation. The only case where Wolbachia is known to play an essential nutritional role for its host is the obligate symbiosis between Wolbachia and the bed bug (Cimex lectularius), with Wolbachia providing vitamin B [114-117]. Its role in lignocellulose degradation therefore remains to be experimentally tested. In contrast, no lignocellulose-degrading CAZymes associated with Candidatus Hepatoplasma spp. were identified in this study. These bacteria are widespread facultative symbionts residing in the caeca of terrestrial isopods, and they had been initially thought to be involved in lignocellulose-degradation [41, 42, 46]. However, the genome of Candidatus Hepatoplasma from A. vulgare does not contain any lignocellulose-degrading CAZymes [45]. Nonetheless, the fact that Candidatus Hepatoplasma increases its host's survival on a cellulosic low-quality diet [118] still suggests a nutritional role of the symbiont, although it may not be linked to lignocellulose degradation.

\section{Conclusion}

In accordance with the hypothesis of Zimmer et al. $[38,39]$, our study provides new insights into the contribution of the microbiota to the digestion of terrestrial food sources, which may have enabled the colonization of land by terrestrial isopods. We demonstrate that there is a potential collaboration between $A$. vulgare and its microbiome for an efficient lignocellulose digestion. Despite distinct bacterial communities depending on host origin, microbial functions related to lignocellulose degradation are highly similar between laboratory lineages and natural isopod populations. These functionally redundant bacterial communities may thus have evolved with the shift in the host's diet $[119,120]$, along with digestive mechanisms of the host. However, more detailed functional investigations based on experimental approaches as well as metatranscriptomics or metaproteomics will be necessary to validate the specific functional contributions of each member of the woodlice holobiont. Moreover, the extension of this work to other isopod species will further improve our understanding whether shifts in the host-associated microbiota might indeed have influenced the successful colonization of land by terrestrial isopods.

\section{Additional files}

Additional file 1: Table S1. List of primers used in RT-qPCR. (XLSX $10 \mathrm{~kb}$ ) Additional file 2: Table S2. List of CAZymes identified in metagenome assemblies and in the transcriptome of A. vulgare. (XLSX $18 \mathrm{~kb}$ )

Additional file 3: Protein sequences of identified CAZy genes in metagenome assemblies. (FA 596 kb)

Additional file 4: Protein sequences of identified CAZy genes in A. vulgare transcriptome. (FA $861 \mathrm{~kb}$ )

Additional file 5: Table S3. RPKM values for CAZymes identified in the transcriptome of A. vulgare. (XLSX $50 \mathrm{~kb}$ )

Additional file 6: Table S4. List of predicted enzymatic functions of CAZymes identified in metagenomes and host transcriptome. (XLSX 14 kb)

Additional file 7: Table S5. Comparison of the glycoside hydrolase (GH) profiles of A. vulgare, termite, snail, slug, human, panda, HF cross, jersey cow, cow, reindeer, and macropod gut metagenomes, showing $\mathrm{GH}$ groups that are involved in the breakdown/modification of plant cell wall polysaccharides. (XLSX $14 \mathrm{~kb}$ )

\section{Acknowledgements}

We thank Maryline Raymond for assistance with animal dissections and DNA extractions, Jérôme Lesobre for RNA extraction from the host used in reference transcriptome construction and Alexandra Lafitte for animal rearing.

\section{Funding}

This work was funded by the 2015-2020 State-Region Planning Contracts (CPER), European Regional Development Fund (FEDER) (BiodivUP project, coordinator DB), and intramural funds from the Centre National de la Recherche Scientifique and the University of Poitiers. MB was supported by a PhD grant from the French Ministère de l'Enseignement supérieur, de la Recherche et de l'Innovation.

\section{Availability of data and materials}

Reads used for transcriptome assembly are available from the NCBI Sequence Read Archive (https://www.ncbi.nlm.nih.gov/sra/) under accession numbers SRS625835 and SRS625837-SRS625845. Identified lignocellulose CAZymes are provided in FASTA format in the Additional file 2.

\section{Authors' contributions}

$M B$ performed sequence processing, RT-qPCR, and data analysis, and drafted the manuscript. JD participated in the experimental design, sampled the isopods, tested the presence of major symbionts by PCR assays and sequencing, and prepared the DNA extraction and enrichment for metagenome sequencing. CN performed the assembly of the transcriptome. BM supervised the bioinformatic data analysis for both transcriptome and metagenome. DB and BM supervised the study. DB conceived and designed the study and supervised the statistical data analysis. All authors contributed to the final version of the manuscript. All authors read and approved the final manuscript.

Ethics approval and consent to participate Not applicable. 


\section{Consent for publication}

Not applicable.

\section{Competing interests}

The authors declare that they have no competing interests.

\section{Publisher's Note}

Springer Nature remains neutral with regard to jurisdictional claims in published maps and institutional affiliations.

\section{Author details}

'Laboratoire Ecologie et Biologie des Interactions-UMR CNRS 7267, Equipe Ecologie Evolution Symbiose-Batiment B8-B35, Université de Poitiers, 5 rue Albert Turpain, TSA 51106, F-86073 Poitiers Cedex 9, France. ${ }^{2}$ Dipartimento di Biologia e Biotecnologie, Università degli Studi di Pavia, Pavia, Italy.

\section{Received: 14 July 2018 Accepted: 22 August 2018}

\section{Published online: 17 September 2018}

\section{References}

1. Swift M, Heal O, Anderson J. Decomposition in terrestrial ecosystems. Oxford: Blackwell Scientific Publications; 1979.

2. Hättenschwiler S, Tiunov AV, Scheu S. Biodiversity and litter decomposition in terrestrial ecosystems. Annu Rev Ecol Evol Syst. 2005;36:191-218.

3. David JF. The role of litter-feeding macroarthropods in decomposition processes: a reappraisal of common views. Soil Biol Biochem. 2014;76: 109-18.

4. López-Mondéjar R, Zühlke D, Becher D, Riedel K, Baldrian P. Cellulose and hemicellulose decomposition by forest soil bacteria proceeds by the action of structurally variable enzymatic systems. Sci Rep. 2016;6 https://doi.org/10. 1038/srep25279

5. Ragauskas AJ. The path forward for biofuels and biomaterials. Science. 2006 311:484-9.

6. Himmel ME, Ding S-Y, Johnson DK, Adney WS, Nimlos MR, Brady JW, et al. Biomass recalcitrance: engineering plants and enzymes for biofuels production. Science. 2007;315:804-7.

7. Madeira JV, Contesini FJ, Calzado F, Rubio MV, Zubieta MP, Lopes DB, et al Agro-industrial residues and microbial enzymes. Biotechnology of microbial enzymes. Cambridge: Elsevier; 2017. p. 475-511. https://doi.org/10.1016/ B978-0-12-803725-6.00018-2.

8. Payne CM, Knott BC, Mayes HB, Hansson H, Himmel ME, Sandgren M, et al. Fungal Cellulases. Chem Rev. 2015;115:1308-448.

9. Argyropoulos DS, Menachem SB. Lignin. Biotechnol Pulp Pap Ind. 1997;57: 127-58

10. Anderson WF, Akin DE. Structural and chemical properties of grass lignocelluloses related to conversion for biofuels. J Ind Microbiol Biotechnol. 2008;35:355-66.

11. Scharf ME, Tartar A. Termite digestomes as sources for novel lignocellulases. Biofuels Bioprod Biorefin. 2008;2:540-52.

12. Pollegioni $L$, Tonin F, Rosini E. Lignin-degrading enzymes. FEBS J. 2015;282: 1190-213.

13. Sjöström E. Wood chemistry: fundamentals and applications. San Diego: Academic Press; 1993

14. Horn SJ, Vaaje-Kolstad G, Westereng B, Eijsink V. Novel enzymes for the degradation of cellulose. Biotechnol Biofuels. 2012:5:45.

15. de Souza WR. Microbial Degradation of Lignocellulosic Biomass. In: Chandel A, editor. Sustainable Degradation of Lignocellulosic Biomass - Techniques, Applications and Commercialization. InTech; 2013. https://doi.org/10.5772/54325.

16. Himmel ME, Xu Q, Luo Y, Ding S-Y, Lamed R, Bayer EA. Microbial enzyme systems for biomass conversion: emerging paradigms. Biofuels. 2010;1:323-41.

17. Bomble YJ, Lin C-Y, Amore A, Wei H, Holwerda EK, Ciesielski PN, et al. Lignocellulose deconstruction in the biosphere. Curr Opin Chem Biol. 2017; 41:61-70.

18. Kaoutari AE, Armougom F, Gordon Jl, Raoult D, Henrissat B. The abundance and variety of carbohydrate-active enzymes in the human gut microbiota. Nat Rev Microbiol. 2013:11:497-504.

19. Watanabe H, Tokuda G. Cellulolytic systems in insects. Annu Rev Entomol. 2010:55:609-32

20. Cragg SM, Beckham GT, Bruce NC, Bugg TD, Distel DL, Dupree P, et al. Lignocellulose degradation mechanisms across the tree of life. Curr Opin Chem Biol. 2015;29:108-19.
21. Nakashima K, Watanabe H, Saitoh H, Tokuda G, Azuma J-I. Dual cellulosedigesting system of the wood-feeding termite, Coptotermes formosanus Shiraki. Insect Biochem Mol Biol. 2002;32:777-84.

22. Zilber-Rosenberg I, Rosenberg E. Role of microorganisms in the evolution of animals and plants: the hologenome theory of evolution. FEMS Microbiol Rev. 2008;32:723-35.

23. Geng A, Cheng Y, Wang Y, Zhu D, Le Y, Wu J, et al. Transcriptome analysis of the digestive system of a wood-feeding termite (Coptotermes formosanus) revealed a unique mechanism for effective biomass degradation. Biotechnol Biofuels. 2018;11 https://doi.org/10.1186/s13068-018-1015-1.

24. Tartar A, Wheeler MM, Zhou X, Coy MR, Boucias DG, Scharf ME. Parallel metatranscriptome analyses of host and symbiont gene expression in the gut of the termite Reticulitermes flavipes. Biotechnol Biofuels. 2009;2:25.

25. Poulsen M, Hu H, Li C, Chen Z, Xu L, Otani S, et al. Complementary symbiont contributions to plant decomposition in a fungus-farming termite. Proc Natl Acad Sci. 2014;111:14500-5.

26. Liu N, Zhang L, Zhou H, Zhang M, Yan X, Wang Q, et al. Metagenomic insights into metabolic capacities of the gut microbiota in a funguscultivating termite (Odontotermes yunnanensis). PLoS One. 2013:8:e69184.

27. Ni J, Tokuda G. Lignocellulose-degrading enzymes from termites and their symbiotic microbiota. Biotechnol Adv. 2013;31:838-50.

28. Brune A. Symbiotic digestion of lignocellulose in termite guts. Nat Rev Microbiol. 2014;12:168-80.

29. Joly F-X, Coulis M, Gérard A, Fromin N, Hättenschwiler S. Litter-type specific microbial responses to the transformation of leaf litter into millipede feces. Soil Biol Biochem. 2015:86:17-23.

30. Špaldoňová A, Frouz J. The role of Armadillidium vulgare (Isopoda: Oniscidea) in litter decomposition and soil organic matter stabilization. Appl Soil Ecol. 2014;83:186-92.

31. Abd El-Wakeil KF. Effects of terrestrial isopods (Crustacea: Oniscidea) on leaf litter decomposition processes. J Basic Appl Zool. 2015;69:10-6.

32. Souty-Grosset C, Badenhausser I, Reynolds JD, Morel A. Investigations on the potential of woodlice as bioindicators of grassland habitat quality. Eur J Soil Biol. 2005:41:109-16.

33. Mocquard JP, Juchault P, Jambu P, Fustec E, Lebourg B. Essai d'évaluation du rôle des crustacés oniscoïdes dans la transformation des litières végétales dans une forêt feuillue de l'ouest de la France. Rev Écol Biol Sol. 1987;3:311-27.

34. Jambu P, Juchault P, Mocquard JP. Étude expérimentale de la contribution du crustacé isopode Oniscus asellus à la transformation des litières forestières sous chêne sessile. Pedobiologia. 1988:32:147-56.

35. Zimmer M, Kautz G, Topp W. Do woodlice and earthworms interact synergistically in leaf litter decomposition? Funct Ecol. 2005:19:7-16.

36. Hassall M. The functional morphology of the mouthparts and foregut in the terrestrial isopod Philoscia muscorum. Crustaceana. 1977;33:225-36.

37. Jia $Y, L v Y$, Kong $X$, Jia $X$, Tian $K, D u$ J, et al. Insight into the indirect function of isopods in litter decomposition in mixed subtropical forests in China. Appl Soil Ecol. 2015:86:174-81.

38. Zimmer M, Danko JP, Pennings SC, Danford AR, Ziegler A, Uglow RF, et al. Hepatopancreatic endosymbionts in coastal isopods (Crustacea: Isopoda), and their contribution to digestion. Mar Biol. 2001;138:955-63.

39. Zimmer M. Nutrition in terrestrial isopods (Isopoda: Oniscidea): an evolutionary-ecological approach. Biol Rev. 2002;77:455-93.

40. Zimmer M, Bartholmé S. Bacterial endosymbionts in Asellus aquaticus (Isopoda) and Gammarus pulex (Amphipoda) and their contribution to digestion. Limnol Oceanogr. 2003:48:2208-13.

41. Wang Y, Brune A, Zimmer M. Bacterial symbionts in the hepatopancreas of isopods: diversity and environmental transmission: bacterial symbionts in isopods. FEMS Microbiol Ecol. 2007;61:141-52.

42. Bouchon D, Zimmer M, Dittmer J. The terrestrial isopod microbiome: an allin-one toolbox for animal-microbe interactions of ecological relevance. Front Microbiol. 2016;7 https://doi.org/10.3389/fmicb.2016.01472.

43. Anton-Erxleben F, Zimmer M, Brune A, Wang Y, Stingl U. Candidatus Hepatincola porcellionum gen. nov., sp. nov., a new, stalk-forming lineage of Rickettsiales colonizing the midgut glands of a terrestrial isopod. Arch Microbiol. 2004;181:299-304.

44. Wang Y, Stingl U, Anton-Erxleben F, Geisler S, Brune A, Zimmer M. "Candidatus Hepatoplasma crinochetorum" a new, stalk-forming lineage of Mollicutes colonizing the midgut glands of a terrestrial isopod. Appl Environ Microbiol. 2004:70:6166-72.

45. Leclercq S, Dittmer J, Bouchon D, Cordaux R. Phylogenomics of "Candidatus Hepatoplasma crinochetorum," a lineage of Mollicutes associated with noninsect arthropods. Genome Biol Evol. 2014;6:407-15. 
46. Zimmer M. The role of animal-microbe interactions in isopod ecology and evolution. Acta Biol Benrodis. 2006;13:127-68.

47. King AJ, Cragg SM, Li Y, Dymond J, Guille MJ, Bowles DJ, et al. Molecular insight into lignocellulose digestion by a marine isopod in the absence of gut microbes. Proc Natl Acad Sci. 2010;107:5345-50.

48. Kostanjšek R, Milatovič M, Štrus J. Endogenous origin of endo- $\beta-1,4-$ glucanase in common woodlouse Porcellio scaber (Crustacea, Isopoda). J Comp Physiol B. 2010;180:1143-53.

49. Kern M, McGeehan JE, Streeter SD, Martin RNA, Besser K, Elias L, et al. Structural characterization of a unique marine animal family 7 cellobiohydrolase suggests a mechanism of cellulase salt tolerance. Proc Natl Acad Sci. 2013;110:10189-94.

50. Dittmer J, Beltran-Bech S, Lesobre J, Raimond M, Johnson M, Bouchon D. Host tissues as microhabitats for Wolbachia and quantitative insights into the bacterial community in terrestrial isopods. Mol Ecol. 2014;23:2619-35.

51. Dittmer J, Lesobre J, Moumen B, Bouchon D. Host origin and tissue microhabitat shaping the microbiota of the terrestrial isopod Armadillidium vulgare. FEMS Microbiol Ecol. 2016;92:fiw063.

52. Dittmer J, Bouchon D. Feminizing Wolbachia influence microbiota composition in the terrestrial isopod Armadillidium vulgare. Sci Rep. 2018;8 https://doi.org/10.1038/s41598-018-25450-4

53. Romiguier J, Gayral P, Ballenghien M, Bernard A, Cahais V, Chenuil A, et al. Comparative population genomics in animals uncovers the determinants of genetic diversity. Nature. 2014;515:261-3.

54. Langmead B, Trapnell C, Pop M, Salzberg SL. Ultrafast and memory-efficient alignment of short DNA sequences to the human genome. Genome Biol. 2009:10:R25.

55. Martin M. Cutadapt removes adapter sequences from high-throughput sequencing reads. EMBnet J. 2011;17:10

56. Zerbino DR, Birney E. Velvet: algorithms for de novo short read assembly using de Bruijn graphs. Genome Res. 2008;18:821-9.

57. Schulz MH, Zerbino DR, Vingron M, Birney E. Oases: robust de novo RNAseq assembly across the dynamic range of expression levels. Bioinformatics. 2012;28:1086-92.

58. Li W, Godzik A. Cd-hit: a fast program for clustering and comparing large sets of protein or nucleotide sequences. Bioinformatics. 2006;22:1658-9.

59. Altschul SF, Gish W, Miller W, Myers EW, Lipman DJ. Basic local alignment search tool. J Mol Biol. 1990;215:403-10.

60. Simão FA, Waterhouse RM, loannidis P, Kriventseva EV, Zdobnov EM. BUSCO: assessing genome assembly and annotation completeness with single-copy orthologs. Bioinformatics. 2015;31:3210-2.

61. Mortazavi A, Williams BA, McCue K, Schaeffer L, Wold B. Mapping and quantifying mammalian transcriptomes by RNA-Seq. Nat Methods. 2008:5:621-8.

62. Kocher TD, Thomas WK, Meyer A, Edwards SV, Pääbo S, Villablanca FX, et al. Dynamics of mitochondrial DNA evolution in animals: amplification and sequencing with conserved primers. Proc Natl Acad Sci. 1989;86:6196-200

63. Bolger AM, Lohse M, Usadel B. Trimmomatic: a flexible trimmer for Illumina sequence data. Bioinformatics. 2014;30:2114-20.

64. Li D, Luo R, Liu C-M, Leung C-M, Ting H-F, Sadakane K, et al. MEGAHIT v1.0: a fast and scalable metagenome assembler driven by advanced methodologies and community practices. Methods. 2016;102:3-11.

65. Lombard V, Golaconda Ramulu H, Drula E, Coutinho PM, Henrissat B. The carbohydrate-active enzymes database (CAZy) in 2013. Nucleic Acids Res. 2014;42:D490-5.

66. Hyatt D, LoCascio PF, Hauser $\amalg$, Uberbacher EC. Gene and translation initiation site prediction in metagenomic sequences. Bioinformatics. 2012;28:2223-30.

67. Yin $Y$, Mao $X$, Yang J, Chen X, Mao F, Xu Y. dbCAN: a web resource for automated carbohydrate-active enzyme annotation. Nucleic Acids Res. 2012;40:W445-51.

68. Mistry J, Finn RD, Eddy SR, Bateman A, Punta M. Challenges in homology search: HMMER3 and convergent evolution of coiled-coil regions. Nucleic Acids Res. 2013;41:e121.

69. Busk PK, Pilgaard B, Lezyk MJ, Meyer AS, Lange L. Homology to peptide pattern for annotation of carbohydrate-active enzymes and prediction of function. BMC Bioinformatics. 2017;18 https://doi.org/10.1186/s12859-0171625-9.

70. Huson DH, Beier S, Flade I, Górska A, El-Hadidi M, Mitra S, et al. MEGAN community edition-interactive exploration and analysis of large-scale microbiome sequencing data. PLoS Comput Biol. 2016;12:e1004957.

71. McMurdie PJ, Holmes S. Phyloseq: an R package for reproducible interactive analysis and graphics of microbiome census data. PLoS One. 2013;8:e61217.
72. Krzywinski M, Schein J, Birol I, Connors J, Gascoyne R, Horsman D, et al. Circos: an information aesthetic for comparative genomics. Genome Res. 2009;19:1639-45.

73. Rozen S, Skaletsky H. Primer3 on the WWW for General Users and for Biologist Programmers.Methods Mol Biol. 2000;132:365-86.

74. Chevalier F, Herbinière-Gaboreau J, Charif D, Mitta G, Gavory F, Wincker P, et al. Feminizing Wolbachia: a transcriptomics approach with insights on the immune response genes in Armadillidium vulgare. BMC Microbiol. 2012; 12(Suppl 1):S1.

75. Cardoso AM, Cavalcante JJV, Cantão ME, Thompson CE, Flatschart RB, Glogauer A, et al. Metagenomic analysis of the microbiota from the crop of an invasive snail reveals a rich reservoir of novel genes. PLoS One. 2012;7: e48505.

76. Allgaier M, Reddy A, Park JI, Ivanova N, D'haeseleer P, Lowry S, et al. Targeted discovery of glycoside hydrolases from a switchgrass-adapted compost community. PLoS One. 2010;5:e8812

77. Urzi C, De Leo F, Passo CL, Criseo G. Intra-specific diversity of Aureobasidium pullulans strains isolated from rocks and other habitats assessed by physiological methods and by random amplified polymorphic DNA (RAPD). J Microbiol Methods. 1999;36:95-105.

78. Warnecke F, Luginbühl P, Ivanova N, Ghassemian M, Richardson TH, Stege JT, et al. Metagenomic and functional analysis of hindgut microbiota of a wood-feeding higher termite. Nature. 2007;450:560-5.

79. He S, Ivanova N, Kirton E, Allgaier M, Bergin C, Scheffrahn RH, et al. Comparative metagenomic and metatranscriptomic analysis of hindgut paunch microbiota in wood- and dung-feeding higher termites. PLoS One. 2013:8:e61126.

80. Isroi MR, Syamsiah S, Niklasson C, Cahyanto MN, Lundquist K, et al. Biotechnology in the pulp and paper industry. Bioresources. 2011;6:5224-59.

81. Zimmer M, Brune A. Physiological properties of the gut lumen of terrestrial isopods (Isopoda: Oniscidea): adaptive to digesting lignocellulose? J Comp Physiol B. 2005;175:275-83.

82. Zimmer M. The fate and effects of ingested hydrolyzable tannins in Porcellio scaber. J Chem Ecol. 1999;25:611-28.

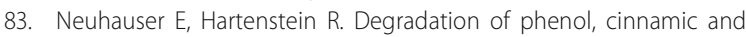
quinic acid in the terrestrial crustacean, Oniscus asellus. Soil Biol Biochem. 1976;8:95-8.

84. Dittmer NT, Suderman RJ, Jiang H, Zhu Y-C, Gorman MJ, Kramer KJ, et al. Characterization of cDNAs encoding putative laccase-like multicopper oxidases and developmental expression in the tobacco hornworm, Manduca sexta, and the malaria mosquito, Anopheles gambiae. Insect Biochem Mol Biol. 2004;34:29-41.

85. Henriksson G, Johansson G, Pettersson G. A critical review of cellobiose dehydrogenases. J Biotechnol. 2000;78:93-113.

86. Ludwig R, Harreither W, Tasca F, Gorton L. Cellobiose dehydrogenase: a versatile catalyst for electrochemical applications. ChemPhysChem. 2010;11: 2674-97.

87. Tarmadi D, Tobimatsu Y, Yamamura M, Miyamoto T, Miyagawa Y, Umezawa T, et al. NMR studies on lignocellulose deconstructions in the digestive system of the lower termite Coptotermes formosanus Shiraki. Sci Rep. 2018; 8 https://doi.org/10.1038/s41598-018-19562-0.

88. Li H, Yelle DJ, Li C, Yang M, Ke J, Zhang R, et al. Lignocellulose pretreatment in a fungus-cultivating termite. Proc Natl Acad Sci. 2017;114:4709-14.

89. Rytioja J, Hildén K, Yuzon J, Hatakka A, de Vries RP, Mäkelä MR. Plantpolysaccharide-degrading enzymes from basidiomycetes. Microbiol Mol Biol Rev. 2014;78:614-49.

90. Fischer R, Ostafe R, Twyman RM. Cellulases from Insects. In: Vilcinskas A, editor. Yellow Biotechnology II. Berlin, Heidelberg: Springer Berlin Heidelberg; 2013. p. 51-64. https://doi.org/10.1007/10_2013_206.

91. Kao D, Lai AG, Stamataki E, Rosic S, Konstantinides N, Jarvis E, et al. The genome of the crustacean Parhyale hawaiensis, a model for animal development, regeneration, immunity and lignocellulose digestion. elife. 2016;5:e20062.

92. Allardyce BJ, Linton SM, Saborowski R. The last piece in the cellulase puzzle: the characterisation of -glucosidase from the herbivorous gecarcinid land crab Gecarcoidea natalis. J Exp Biol. 2010;213:2950-7.

93. Calderón-Cortés N, Quesada M, Watanabe H, Cano-Camacho H, Oyama K. Endogenous plant Cell Wall digestion: a key mechanism in insect evolution. Annu Rev Ecol Evol Syst. 2012;43:45-71.

94. Hames CAC, Hopkin SP. The structure and function of the digestive system of terrestrial isopods. J Zool. 1989;217:226-36. 
95. Zimmer M, Topp W. Microorganisms and cellulose digestion in the gut of the woodlouse Porcellio scaber. J Chem Ecol. 1998;24:1397-408.

96. Linton SM, Greenaway P. A review of feeding and nutrition of herbivorous land crabs: adaptations to low quality plant diets. J Comp Physiol B. 2007; 177:269-86.

97. Allardyce BJ, Linton SM. Purification and characterisation of endo- -1,4 glucanase and laminarinase enzymes from the gecarcinid land crab Gecarcoidea natalis and the aquatic crayfish Cherax destructor. J Exp Biol. 2008;211:2275-87

98. Linton SM, Saborowski R, Shirley AJ, Penny JA. Digestive enzymes of two brachyuran and two anomuran land crabs from Christmas Island, Indian Ocean. J Comp Physiol B. 2014;184:449-68.

99. Sukharnikov LO, Cantwell BJ, Podar M, Zhulin IB. Cellulases: ambiguous nonhomologous enzymes in a genomic perspective. Trends Biotechnol. 2011;29:473-9.

100. Rossmassler K, Dietrich C, Thompson C, Mikaelyan A, Nonoh JO, Scheffrahn $\mathrm{RH}$, et al. Metagenomic analysis of the microbiota in the highly compartmented hindguts of six wood- or soil-feeding higher termites. Microbiome. 2015;3 https://doi.org/10.1186/s40168-015-0118-1.

101. Rizzi A, Crotti E, Borruso L, Jucker C, Lupi D, Colombo M, et al. Characterization of the bacterial community associated with larvae and adults of Anoplophora chinensis collected in Italy by culture and cultureindependent methods. Biomed Res Int. 2013;2013:1-12.

102. Degli Esposti M, Martinez Romero E. The functional microbiome of arthropods. PLoS One. 2017;12:e0176573.

103. Gao Z, Ruan L, Chen X, Zhang Y, Xu X. A novel salt-tolerant endo- $\beta$-1,4glucanase Cel5A in Vibrio sp. G21 isolated from mangrove soil. Appl Microbiol Biotechnol. 2010;87:1373-82.

104. O'Dell KB, Woo HL, Utturkar S, Klingeman D, Brown SD, Hazen TC. Genome sequence of Halomonas sp. strain KO116, an ionic liquid-tolerant marine bacterium isolated from a lignin-enriched seawater microcosm. Genome Announc. 2015;3:e00402-15.

105. Okeke BC, Lu J. Characterization of a defined cellulolytic and Xylanolytic bacterial consortium for bioprocessing of cellulose and hemicelluloses. Appl Biochem Biotechnol. 2011;163:869-81.

106. Ventorino V, Aliberti A, Faraco V, Robertiello A, Giacobbe S, Ercolini D, et al. Exploring the microbiota dynamics related to vegetable biomasses degradation and study of lignocellulose-degrading bacteria for industrial biotechnological application. Sci Rep. 2015;5 https://doi.org/10.1038/srep08161.

107. Song J-M, Wei D-Z. Production and characterization of cellulases and xylanases of Cellulosimicrobium cellulans grown in pretreated and extracted bagasse and minimal nutrient medium M9. Biomass Bioenergy. 2010;34: 1930-4.

108. Větrovský T, Steffen KT, Baldrian P. Potential of Cometabolic transformation of polysaccharides and lignin in lignocellulose by soil Actinobacteria. PLoS One. 2014;9:e89108.

109. Wang L, Nie Y, Tang Y-Q, Song X-M, Cao K, Sun L-Z, et al. Diverse bacteria with lignin degrading potentials isolated from two ranks of coal. Front Microbiol. 2016;7 https://doi.org/10.3389/fmicb.2016.01428.

110. Stieglmeier M, Klingl A, Alves RJE, Rittmann SK-MR, Melcher M, Leisch N, et al. Nitrososphaera viennensis gen. Nov., sp. nov., an aerobic and mesophilic, ammonia-oxidizing archaeon from soil and a member of the archaeal phylum Thaumarchaeota. Int J Syst Evol Microbiol. 2014;64(Pt 8):2738-52.

111. Lehtovirta-Morley LE, Ross J, Hink L, Weber EB, Gubry-Rangin C, Thion C, et al. Isolation of ' Candidatus Nitrosocosmicus franklandus', a novel ureolytic soil archaeal ammonia oxidiser with tolerance to high ammonia concentration. FEMS Microbiol Ecol. 2016:92:fiw057.

112. Bouchon D, Cordaux R, Grève P. Rickettsiella, intracellular pathogens of arthropods. Manip Tenants Bact Assoc Arthropods. 2011;2:127.

113. Tsuchida T, Koga R, Fujiwara A, Fukatsu T. Phenotypic effect of "Candidatus Rickettsiella viridis," a facultative symbiont of the pea aphid (Acyrthosiphon pisum), and its interaction with a coexisting symbiont. Appl Environ Microbiol. 2014;80:525-33.

114. Hosokawa T, Koga R, Kikuchi Y, Meng X-Y, Fukatsu T. Wolbachia as a bacteriocyte-associated nutritional mutualist. Proc Natl Acad Sci. 2010;107: 769-74

115. Nikoh N, Hosokawa T, Moriyama M, Oshima K, Hattori M, Fukatsu T. Evolutionary origin of insect-Wolbachia nutritional mutualism. Proc Natl Acad Sci. 2014;111:10257-62.

116. Jiggins FM. Open questions: how does Wolbachia do what it does? BMC Biol. 2016;14 https://doi.org/10.1186/s12915-016-0312-z.
117. McLean AHC, Parker BJ, Hrček J, Henry LM, Godfray HCJ. Insect symbionts in food webs. Philos Trans R Soc B Biol Sci. 2016;371:20150325.

118. Fraune S, Zimmer M. Host-specificity of environmentally transmitted mycoplasma-like isopod symbionts: specific association of mycoplasms and isopods. Environ Microbiol. 2008;10:2497-504.

119. Horvathova T, Babik W, Bauchinger U. Biofilm feeding: microbial colonization of food promotes the growth of a detritivorous arthropod. ZooKeys. 2016;577:25-41.

120. Scott KP, Gratz SW, Sheridan PO, Flint HJ, Duncan SH. The influence of diet on the gut microbiota. Pharmacol Res. 2013;69:52-60.
Ready to submit your research? Choose BMC and benefit from:

- fast, convenient online submission

- thorough peer review by experienced researchers in your field

- rapid publication on acceptance

- support for research data, including large and complex data types

- gold Open Access which fosters wider collaboration and increased citations

- maximum visibility for your research: over $100 \mathrm{M}$ website views per year

At BMC, research is always in progress.

Learn more biomedcentral.com/submissions 